\title{
Phenylquinoxalinone CFTR activator as potential pro-secretory therapy for constipation
}

Onur Cil ${ }^{\mathrm{a}}$, Puay-Wah Phuan ${ }^{\mathrm{a}}$, Jung-Ho Son ${ }^{\mathrm{b}}$, Jie S. Zhu ${ }^{\mathrm{b}}$, Colton K. Ku ${ }^{\mathrm{b}}$, Niloufar Akhavan Tabib ${ }^{\mathrm{b}}$, Andrew P. Teuthorn ${ }^{\mathrm{b}}$, Loretta Ferrera ${ }^{\mathrm{c}}$, Nicholas C. Zachos ${ }^{\mathrm{d}}$, Ruxian Lin ${ }^{\mathrm{d}}$, Luis J.V. Galietta ${ }^{\mathrm{c}}$, Mark Donowitz ${ }^{\mathrm{d}}$, Mark J. Kurth ${ }^{\mathrm{b}}$ and A.S. Verkman ${ }^{\mathrm{a}}$

${ }^{a}$ Departments of Medicine and Physiology, University of California San Francisco, San Francisco, CA 94143, USA

${ }^{\mathrm{b}}$ Department of Chemistry, University of California, Davis, CA, 95616, USA

${ }^{\mathrm{c}}$ Istituto Giannina Gaslini, via Gerolamo Gaslini 5, Genova 16147, Italy

${ }^{\mathrm{d}}$ Departments of Physiology and Medicine, Gastroenterology Division, Johns Hopkins University School of Medicine, Baltimore, MD 21205, USA

Correspondence: Alan S. Verkman, M.D. Ph.D., 1246 Health Sciences East Tower, University of California, San Francisco, CA 94143-0521, USA. Phone: 415-4768530, Fax: 415-6653847, E-mail: Alan.Verkman@ucsf.edu

Running head: CFTR activators as novel laxatives Abbreviations: cystic fibrosis transmembrane conductance regulator (CFTR), chronic idiopathic constipation (CIC), opioid-induced constipation (OIC), constipation-predominant irritable bowel syndrome (IBS-C), parts per million (ppm), phosphate-buffered saline (PBS), liquid chromatography mass spectrometry (LC/MS), endothelin receptor B (Ednrb). 


\section{ABSTRACT}

Constipation is a common condition for which current treatments can have limited efficacy. By high-throughput screening we recently identified a phenylquinoxalinone activator of the cystic fibrosis transmembrane conductance regulator (CFTR) chloride channel that stimulated intestinal fluid secretion and normalized stool output in a mouse model of opioid-induced constipation (Cil et al. Cell Mol Gastroenterol Hepatol 2:317-327, 2016). Here, we report phenylquinoxalinone structure-activity analysis, mechanism of action, animal efficacy data in acute and chronic models of constipation, and functional data in ex vivo primary cultured human enterocytes. Structure-activity analysis was done on 175 phenylquinoxalinone analogs, including 15 synthesized compounds. The most potent compound,

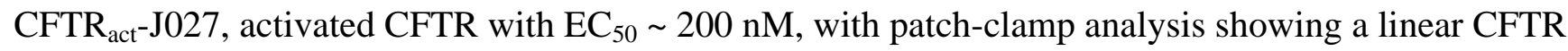
current-voltage relationship with direct CFTR activation. CFTR $_{\text {act }} \mathrm{J} 027$ corrected reduced stool output and hydration in a mouse model of acute constipation produced by scopolamine and in a chronically constipated mouse strain $(\mathrm{C} 3 \mathrm{H} / \mathrm{HeJ})$. Direct comparison with the approved pro-secretory drugs lubiprostone and linaclotide showed substantially greater intestinal fluid secretion with $\mathrm{CFTR}_{\text {act }}{ }^{-\mathrm{J} 027}$, as well as greater efficacy in a constipation model. As evidence to support efficacy in human constipation, $\mathrm{CFTR}_{\text {act }}-\mathrm{J} 027$ increased transepithelial fluid transport in enteroids generated from normal human small

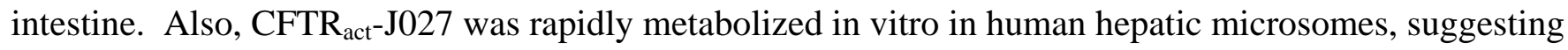
minimal systemic exposure upon oral administration. These data establish structure-activity and mechanistic data for phenylquinoxalinone CFTR activators, and support their potential efficacy in human constipation. 


\section{INTRODUCTION}

Constipation is a common clinical problem affecting $15 \%$ of the U.S. population, with annual health-care costs estimated at $\sim 7$ billion dollars of which $>800$ million dollars is spent on laxatives (1). The most frequent types of constipation include chronic idiopathic constipation (CIC), opioid-induced constipation (OIC) and constipation-predominant irritable bowel syndrome (IBS-C). Current treatment options include dietary modification and over-the-counter laxatives including agents that increase stool bulk, soften stool, create an osmotic load, or stimulate intestinal contraction (2). There are three FDAapproved prescription drugs for treatment of various types of constipation: linaclotide, a peptide agonist of the guanylate cyclase $\mathrm{C}$ receptor that acts by inhibiting visceral pain, stimulating intestinal motility, and increasing intestinal secretion (3); lubiprostone, a prostaglandin $\mathrm{E}$ analog that is thought to activate the enterocyte ClC-2 channel and perhaps CFTR $(4,5)$; and naloxegol, a peripherally acting $\mu$-opioid receptor antagonist (6). These FDA-approved drugs generally showed efficacy in 40-50\% of patients in different clinical trials albeit with a baseline 25-35\% patient response to placebo (7-9). Despite the wide range of therapeutic options, there is a continued need for safe and effective drugs to treat constipation.

We recently introduced the idea of prosecretory therapy for constipation by direct activation of the cystic fibrosis transmembrane conductance regulator (CFTR) $\mathrm{Cl}^{-}$channel, based on the idea that increasing intestinal fluid secretion would increase stool hydration and thereby accelerate intestinal transit. Intestinal fluid secretion involves active $\mathrm{Cl}^{-}$secretion across the enterocyte epithelium, which is controlled by apical membrane $\mathrm{Cl}^{-}$channels, including CFTR and perhaps $\mathrm{Ca}^{2+}$-activated $\mathrm{Cl}^{-}$channels. CFTR is a compelling target for constipation therapy as its overactivation by bacterial enterotoxins in cholera and Traveler's diarrhea (enterotoxigenic E. coli) produces marked intestinal fluid secretion (10, 11). We recently reported that the phenylquinoxalinone $\mathrm{CFTR}_{\text {act }} \mathrm{J} 027$, a small-molecule CFTR activator identified by high-throughput screening, increased intestinal fluid secretion and normalized stool output, 
stool water content and intestinal transit in a mouse model of acute constipation produced by loperamide (12). The compound had no effect in CFTR-deficient mice, showed no toxicity, and had minimal systemic exposure following oral administration because of rapid hepatic metabolism.

Here, for development of phenylquinoxalinones for therapy of constipation, we studied compound structure-activity relationships, mechanism of action by patch-clamp analysis, and animal efficacy in acute and chronic rodent models of constipation. In addition, functional studies were done in human enterocytes to support their potential utility for treatment of constipation in humans.

\section{MATERIALS AND METHODS}

\section{General chemistry procedures}

All chemicals were purchased from commercial suppliers and used without further purification. Commercial analogs were purchased from ChemDiv (San Diego, CA). All other chemicals were purchased from Sigma-Aldrich (St. Louis, MO) unless otherwise stated. Analytical thin layer chromatography was carried out on pre-coated plates (silica gel 60 F254, $250 \mu \mathrm{m}$ thickness) and visualized with UV light. Flash chromatography was performed using $60 \AA$ A, 32-63 $\mu \mathrm{m}$ silica gel (Fisher Scientific, Waltham, MA). Concentration in vacuo refers to rotary evaporation under reduced pressure. ${ }^{1} \mathrm{H}$ NMR spectra were recorded at 400, 600, or $800 \mathrm{MHz}$ at ambient temperature with acetoned6, DMSO-d6 or $\mathrm{CDCl}_{3}$ as solvents. ${ }^{13} \mathrm{C}$ NMR spectra were recorded at 100, 150, or $200 \mathrm{MHz}$ at ambient temperature. Chemical shifts are reported in parts per million (ppm) relative to the residual solvent peak. High-resolution mass spectra were acquired on an LTQ Orbitrap XL mass spectrometer equipped with an electrospray ionization source (ThermoFisher, San Jose, CA), operating in the positive ion mode. Samples were introduced into the source via loop injection at a flow rate of $200 \mu \mathrm{L} / \mathrm{min}$ in a solvent system of 1:1 acetonitrile/water with $0.1 \%$ formic acid. Mass spectra were acquired using 
Xcalibur, version 2.0.7 SP1 (ThermoFinnigan, San Jose, CA). The spectra were externally calibrated using the standard calibration mixture and then calibrated internally to $<2$ ppm with the lock mass tool. Analytical data are reported in Supplemental Data.

Synthesis of CFTRact-J102-J105, J109, J134-J141 (Path I)

Path I/RXN 1: N-benzyl-R ${ }^{2}$-substituted-2-nitroanilines (1). A stirred solution of $\mathrm{R}^{2}$-substituted2-nitroaniline ( $4 \mathrm{mmol})$ and benzyl bromide $(5 \mathrm{mmol})$ in water $(8 \mathrm{~mL})$ was sealed in a thick-wall glass tube $(10 \mathrm{~mL})$ and heated at $110^{\circ} \mathrm{C}$ overnight. The reaction mixture was cooled to room temperature, diluted with ethyl acetate, and solid sodium bicarbonate $(4 \mathrm{mmol})$ was added. The resulting mixture was washed with water and the organic layer was dried over $\mathrm{MgSO}_{4}$. After filtration, the organic layer was concentrated in vacuo and the final product was purified by silica gel column chromatography to yield brightly colored nitroaniline $\mathbf{1}$.

Path I/RXN 2: $N^{1}$-benzyl-R ${ }^{2}$-substituted-1,2-diaminobenzene (2). Nitroaniline 1 (5 mmol) was dissolved in ethanol ( $100 \mathrm{~mL}$; requires warming) and, after cooling to room temperature, $\mathrm{Zn}$ (50 mmol) and a $4 \mathrm{M} \mathrm{HCl}(4 \mathrm{~mL})$ were added to the solution. The mixture was stirred until brightly colored 1 was consumed at which point the solution was filtered through a pad of Celite and the solvent was removed in vacuo. The residue was dissolved in ethyl acetate and the mixture was neutralized with $1 \mathrm{M} \mathrm{NaOH}$. The ethyl acetate solution was washed with water, dried over $\mathrm{MgSO}_{4}$, filtered, and concentrated in vacuo. The product was purified by silica gel column chromatography to yield $\mathbf{2}$ as a dark colored viscous oil.

Path I/RXN 3: N-(2-(4-benzyl-R ${ }^{2}$-substituted-3-oxo-3,4-dihydroquinoxalin-2-yl)- $\mathbf{R}^{3}$ substituted-phenyl)acetamide (3). A solution of $2(0.5 \mathrm{mmol})$ and 1-acetyl-( $\mathrm{R}^{3}$-substituted)indoline2,3-dione $(0.5 \mathrm{mmol})$ in glacial acetic acid $(20 \mathrm{~mL})$ was heated at $90{ }^{\circ} \mathrm{C}$ overnight. Upon cooling to 
room temperature the solvent was removed in vacuo and the product was washed with ethanol and filtered to yield 3, which was used without further purification.

\section{Path I/RXN 4: 3-(2-amino-R ${ }^{3}$-substituted-phenyl)-1-benzyl-R ${ }^{2}$-substituted-quinoxalin-2(1H)-} one (4). To a solution of $3(0.2 \mathrm{mmol})$ in methanol $(125 \mathrm{~mL})$ was added $4 \mathrm{M} \mathrm{HCl}(2.5 \mathrm{~mL})$ and the resulting mixture was heated at $80{ }^{\circ} \mathrm{C}$ overnight. Upon cooling to room temperature, the solvent was removed in vacuo and the reaction mixture was neutralized with $1 \mathrm{M} \mathrm{NaOH}$ solution. The product 4 was extracted with ethyl acetate or dichloromethane and purified by flash column chromatography.

\section{Synthesis of CFTRact-J133, J142-144 (Path II)}

Path II/RXN 5: N-( $\mathrm{R}^{3}$-substituted-2-(3-oxo-3,4-dihydroquinoxalin-2-yl)phenyl)acetamide (5). A solution of 1-acetyl-( $\mathrm{R}^{3}$-substituted)indoline-2,3-dione $(1 \mathrm{mmol})$ and $o$-phenylenediamine $(1 \mathrm{mmol})$ in toluene $(10 \mathrm{~mL})$ was heated at $120{ }^{\circ} \mathrm{C}$ overnight. The resulting tan precipitate of $\mathbf{5}$ was collected by filtration, washed sequentially with toluene and hexane, and then used in the next step without further purification.

\section{Path II/RXN 6: N-(2-(4-R ${ }^{1}$-substituted-benzyl-3-oxo-3,4-dihydroquinoxalin-2-yl)-R ${ }^{3}$ -} substituted-phenyl)acetamide (6). A solution of $5(0.5 \mathrm{mmol}), \mathrm{R}^{1}$-substituted benzyl bromide $(0.6$ $\mathrm{mmol})$ and $\mathrm{K}_{2} \mathrm{CO}_{3}(1 \mathrm{mmol})$ in $\mathrm{DMF}(20 \mathrm{~mL})$ was stirred overnight at room temperature. The reaction mixture was diluted with water and extracted with ethyl acetate or dichloromethane. The organic layer was washed sequentially with water and brine and then dried over $\mathrm{MgSO}_{4}$. Filtration and removal of solvent yielded $\mathbf{6}$ as a tan product that was washed with ethanol and used in the deacylation reaction described above without further purification. 


\section{Cell culture}

Fischer Rat Thyroid (FRT) cells stably co-expressing human wildtype CFTR and the halidesensitive yellow fluorescent protein (YFP)-H148Q were as described (13). Cells were cultured on plastic in Coon's-modified Ham's F12 medium supplemented with 10\% fetal bovine serum, 2 mM L-glutamine, 100 units $/ \mathrm{ml}$ penicillin, and $100 \mu \mathrm{g} / \mathrm{ml}$ streptomycin. For platereader assays cells were plated in black 96-well microplates (Corning-Costar Corp., New York, NY) at a density of 20,000 cells per well and assayed 24-48 hours after plating.

\section{Plate reader assay of CFTR activity}

CFTR activity was assayed as described (13). Briefly, cells were washed three times with phosphate-buffered saline (PBS) and then incubated for 10 min with $60 \mu 1$ of PBS containing test compounds (at $10 \mu \mathrm{M})$ and a low concentration of forskolin (125 nM). I- influx was measured in a plate reader by recording fluorescence continuously ( $200 \mathrm{~ms}$ per point) for $2 \mathrm{~s}$ (baseline) and then for $12 \mathrm{~s}$ after rapid (<1 s) addition of $165 \mu \mathrm{L}$ of PBS in which $137 \mathrm{mM} \mathrm{Cl}^{-}$was replaced by $\mathrm{I}^{-}$. The initial rate of $\mathrm{I}^{-}$ influx was computed using exponential regression.

\section{Short-circuit current measurement}

Short-circuit current was measured in FRT cells stably expressing human wildtype CFTR cultured on porous filters as described (14). The basolateral solution contained (in $\mathrm{mM}$ ): $120 \mathrm{NaCl}, 5 \mathrm{KCl}, 1 \mathrm{CaCl}_{2}$, $1 \mathrm{MgCl}_{2}, 10$ glucose, $25 \mathrm{NaHCO}_{3}$ and $5 \mathrm{HEPES}$ ( $\mathrm{pH} 7.4,37^{\circ} \mathrm{C}$ ). In the apical solution $60 \mathrm{mM} \mathrm{NaCl}$ was replaced by $\mathrm{Na}$ gluconate, and $\mathrm{CaCl}_{2}$ was increased to $2 \mathrm{mM}$, and the basolateral membrane was permeabilized with $250 \mu \mathrm{g} / \mathrm{ml}$ amphotericin B. 


\section{Patch-clamp experiments}

Whole-cell and inside-out membrane currents were recorded in FRT cells stably expressing human wildtype CFTR. For whole-cell experiments the extracellular (bath) solution contained (in mM): 150 $\mathrm{NaCl}, 1 \mathrm{CaCl}_{2}, 1 \mathrm{MgCl}_{2}, 10$ glucose, 10 mannitol, $10 \mathrm{Na}-\mathrm{HEPES}$ (pH 7.4). The pipette (intracellular) solution contained (in mM): $120 \mathrm{CsCl}, 10$ TEA-Cl, 0.5 EGTA, $1 \mathrm{MgCl}_{2}, 10$ Cs-HEPES, 40 mannitol, 1 ATP (7.4). For inside-out patch-clamp experiments the pipette solution contained (in mM): $150 \mathrm{~N}$ methyl-D-glucamine chloride (NMDG-Cl), $3 \mathrm{CaCl}_{2}, 2 \mathrm{MgCl}_{2}, 10 \mathrm{Na}-\mathrm{Hepes}$ ( $\mathrm{pH}$ 7.3). The bath solution contained (in mM): 150 NMDG-Cl, $2 \mathrm{MgCl}_{2}, 10$ EGTA, 10 Na-Hepes, 1 ATP (pH 7.3), and 125 nM catalytic subunit of protein kinase A (Promega, Sunnyvale, CA). Pipette electrical resistance for both whole-cell and inside-out experiments was 3-5 M . The protocol for stimulation consisted of 600-ms voltage steps from -100 to $+100 \mathrm{mV}$ in $20 \mathrm{mV}$ increments starting from a holding potential of $-60 \mathrm{mV}$. The interval between steps was $4 \mathrm{~s}$. Membrane currents were filtered at $1 \mathrm{kHz}$ and digitized at $5 \mathrm{kHz}$. Data were analyzed using the Igor software (Wavemetrics, Portland, OR) with custom software kindly provided by Dr. Oscar Moran.

\section{In vitro gastric acid and metabolic stability}

To study gastric acid stability $\mathrm{CFTR}_{\text {act }} \mathrm{J} 027(10 \mu \mathrm{M})$ was dissolved in simulated gastric fluid $(0.2$ $\mathrm{NaCl}, 0.7 \% \mathrm{HCl}, \mathrm{pH}$ 2) and incubated for $3 \mathrm{~h}$ at $37{ }^{\circ} \mathrm{C}$. To study in vitro metabolic stability $\mathrm{CFTR}_{\text {act }}{ }^{-}$ $\mathrm{J} 027(5 \mu \mathrm{M})$ was incubated for specified times at $37{ }^{\circ} \mathrm{C}$ with human liver microsomes ( $1 \mathrm{mg}$ protein $/ \mathrm{ml}$; Sigma-Aldrich) in potassium phosphate buffer $(100 \mathrm{mM})$ containing $1 \mathrm{mM}$ NADPH. After specified incubation periods the mixtures were chilled on ice, and $0.5 \mathrm{ml}$ of ice-cold ethyl acetate was added. Samples were centrifuged for $15 \mathrm{~min}$ at $3000 \mathrm{rpm}$, the supernatants evaporated to dryness, and the residues were dissolved in $100 \mu \mathrm{L}$ mobile phase (acetonitrile:water, 3:1) and assayed by liquid 
chromatography mass spectrometry (LC/MS). The solvent system consisted of a linear gradient from 5 to $95 \%$ acetonitrile over $16 \mathrm{~min}(0.2 \mathrm{ml} / \mathrm{min}$ flow $)$. Mass spectra were acquired on a mass spectrometer (Waters 2695 and Micromass ZQ, Milford, MA) using electrospray (+) ionization, mass ranging from 100 to $1500 \mathrm{Da}$, cone voltage $40 \mathrm{~V}$.

\section{Animals}

Animal experiments were approved by UCSF Institutional Animal Care and Use Committee. Animals were housed in communal cages in a temperature and humidity controlled environment with 12 hour light/dark cycle and provided standard rodent chow and water ad libitum. Wildtype female CD1 mice were bred in the UCSF Laboratory Animal Resource Center. Female C3H/HeJ mice, which have a spontaneous mutation in TLR4 $\left(T l r 4^{l p s-d}\right)$ and their control background $\mathrm{C} 3 \mathrm{H} / \mathrm{HeOuJ}$ mice were purchased from Jackson Laboratories (Bar Harbor, ME).

\section{Constipation models in mice}

CD1 mice (age 8-10 weeks) were administered loperamide $(0.3 \mathrm{mg} / \mathrm{kg})$ or scopolamine $(0.5 \mathrm{mg} / \mathrm{kg})$ intraperitoneally (ip) to induce constipation. CFTR act $^{-} \mathrm{J} 027(10 \mathrm{mg} / \mathrm{kg}$, in saline containing 5\% DMSO and $10 \%$ Kolliphor HS 15) was given ip or orally (po) either $1 \mathrm{~h}$ before, at the same time, or $1 \mathrm{~h}$ after loperamide/scopolamine in different experiments. Control mice were treated with vehicle only. Some mice were treated orally with lubiprostone $(0.5 \mathrm{mg} / \mathrm{kg})$ or linaclotide $(0.5 \mathrm{mg} / \mathrm{kg}$, Toronto Research Chemicals Inc., Toronto, Ontario, Canada). At designated time points mice were placed individually in metabolic cages with food and water provided ad libitum. Stool samples were collected for $3 \mathrm{~h}$, and total stool weight and number of fecal pellets were determined. Stool samples were dried at $80^{\circ} \mathrm{C}$ for $24 \mathrm{~h}$ and stool water content was calculated as [wet weight-dry weight]/wet weight. 
The efficacy of orally administered CFTR act $^{-} \mathrm{J} 027(10 \mathrm{mg} / \mathrm{kg})$ was also tested in a genetically constipated mouse strain (15) $(\mathrm{C} 3 \mathrm{H} / \mathrm{HeJ}$, age $8-11$ weeks) and their wildtype counterparts $(\mathrm{C} 3 \mathrm{H} / \mathrm{HeOuJ}$, age 8-11 weeks). Mice were placed in metabolic cages after CFTR $_{\text {act }}-\mathrm{J} 027$ or vehicle administration at zero time and stool was collected for $4 \mathrm{~h}$. Stool weight, pellet number and water content were determined as described above. Whole-gut transit time was measured to assess gut motility, in which mice treated with CFTR act $^{-} \mathrm{J} 027(10 \mathrm{mg} / \mathrm{kg}$, ip) or vehicle at zero time were given with $100 \mu \mathrm{L}$ blue marker (5\% Evans blue, 5\% gum Arabic) orally. The time of blue dye appearance in stool was determined. All experiments in $\mathrm{C} 3 \mathrm{H} / \mathrm{HeJ}$ and $\mathrm{C} 3 \mathrm{H} / \mathrm{HeOuJ}$ mice were done in paired animals to minimize variability.

\section{Closed-loop model of intestinal fluid secretion}

Mice were given access to 5\% dextrose water but not solid food for $24 \mathrm{~h}$ before experiments. Mice were anesthetized with isoflurane and body temperature was maintained during surgery at $36-38{ }^{\circ} \mathrm{C}$ using a heating pad. A small abdominal incision was made to expose the small intestine, and closed midjejunal loops (length $2-3 \mathrm{~cm}$ ) were isolated by sutures. Loops were injected with $100 \mu \mathrm{L}$ vehicle alone or $100 \mu \mathrm{g}$ CFTR $_{\text {act- }} \mathrm{J} 027$, lubiprostone or linaclotide in vehicle. The abdominal incision was closed with sutures, and mice were allowed to recover from anesthesia. Intestinal loops were removed at $90 \mathrm{~min}$ and loop length and weight were measured to quantify fluid secretion.

\section{Swelling measurements in human enteroids}

Tissues from human subjects were obtained under approval of the Johns Hopkins University School of Medicine Institutional Review Board (protocol NA_00038329). Duodenal and jejunal biopsy specimens were obtained from adults during routine endoscopy at Johns Hopkins Hospital. Crypt 
isolation, enteroid propagation and culture were as described (16). For swelling measurements enteroids were seeded in 35-mm dishes with bottom coverglass with $1.5 \mathrm{~mL}$ media. On the day of the experiment the media was replaced with $3 \mathrm{~mL}$ Advanced DMEM/F12 and enteroids were incubated with $1 \mathrm{mM}$ calcein green-acetoxymethyl ester for $1 \mathrm{~h}$ at $37{ }^{\circ} \mathrm{C}$ to label cytoplasm. Relative enteroid volume following addition of specified concentrations of forskolin was measured using a laser scanning confocal microscope (Fluoview FV10i-LIV; Olympus) at $37{ }^{\circ} \mathrm{C}, 5 \% \mathrm{CO}_{2}$, and $95 \%$ relative humidity. In some studies $\mathrm{CFTR}_{\text {act }} \mathrm{J} 027$ was added $10 \mathrm{~min}$ prior to forskolin. Images were acquired every $10 \mathrm{~min}$ and analyzed with MetaMorph version 7.7 software (Olympus) to quantify enteroid areas.

\section{Statistical analysis}

Experiments with two groups were analyzed with Student's t-test; when there are three or more groups analysis was done with one-way analysis of variance and post-hoc Newman-Keuls multiple comparisons test. $\mathrm{P}<0.05$ was taken as statistically significant.

\section{RESULTS}

\section{Synthesis and structure-activity analysis of phenylquinoxalinone CFTR activators}

Limited structure-activity relationship (SAR) information emerged from analysis of 160 commercially available phenylquinoxalinone analogs, as most had quite different structures or multiple substituent modifications in relation to $\mathrm{CFTR}_{\text {act }} \mathrm{J} 027$. Table 1 reports CFTR activity of selected commercial analogs most closely related to $\mathrm{CFTR}_{\text {act }} \mathrm{J} 027$ (J051 - J062). The benzyl $\left(\mathrm{R}^{1}\right)$ substituent on the phenylquinoxalinone appeared to be important, as unsubstituted (CFTR act $^{-} \mathrm{J}_{051)}$, methyl (CFTR act $^{-}$ J052) and phenylacetyl (CFTR act $^{-}$J058) greatly reduced activity. Limited substitution ( $\mathrm{R}^{2}$ position) on the quinoxalinone ring showed that a nitro group (CFTR $\left.{ }_{\text {act }}-\mathrm{J} 054\right)$ was tolerated. Substituent changes on the 
phenyl ring also strongly modulated activity, for example changing $\mathrm{R}^{3}$ and $\mathrm{R}^{4}$ substituents to N-benzyl and bromo $\left(\mathrm{CFTR}_{\text {act }} \mathrm{J} 056\right)$ or $\mathrm{N}$-acetyl and unsubstituted (CFTR $\mathrm{act}^{-\mathrm{J} 057)}$ greatly reduced activity. Because of the limited information from commercial compounds, synthesis of targeted analogs was undertaken.

Two routes were developed to synthesize the phenylquinoxalinones analogs (Fig. 1A). The Path I route begins with $N$-benzylation of the appropriate 2-nitroaniline $(\rightarrow \mathbf{1})$ and subsequent nitro group reduction to give 1,2-diamino analog $\mathbf{2}$. Condensation of this diamine with the appropriate $N$-acylisatin in acetic acid delivers quinoxalin-2(1H)-one 3; attempts to effect this transformation with non-acylated isatins usually produced the desired product in low yield. Finally, acid-catalyzed deacylation of $\mathbf{3}$ delivered the quinoxalin-2(1H)-one 4. Path II allowed for late-stage introduction of the $N$-benzyl moiety, but requires the use of a symmetrical 1,2-diamine (here, 1,2-diaminobenzene) so as to avoid regioisomer formation in quinoxalin-2(1H)-one 5. $N^{l}$-Benzylation with the appropriate benzyl bromide delivered quinoxalin-2(1H)-one 6 and deacylation gave the quinoxalin-2(1H)-one 4.

CFTR activity was measured using a plate reader assay of iodide influx following extracellular addition of iodide in FRT cells stably expressing human wildtype CFTR and a YFP fluorescent halide sensor. Fig. 1B shows the concentration-dependence data of selected compounds, with $\mathrm{EC}_{50}$ values for all synthesized compounds given in Table 1.

Fig. 1C summarizes structure-activity results for the synthesized compounds reported in Table 1 (compounds with J1\#\# designations). In general, having a substitution group $\left(\mathrm{R}^{1}\right)$ on the benzyl group, especially in the para- or ortho-positions, reduced activity (CFTR act- $^{-} \mathrm{J} 102$, -J103, -J104, -J143, -J144). Acetylation of the amino-group on $\mathrm{CFTR}_{\mathrm{act}}-\mathrm{J} 027$, giving $\mathrm{CFTR}_{\mathrm{act}} \mathrm{J}$ 109, also reduced activity. Analogs with halide substitution at the 6-position $\left(\mathrm{R}^{2}\right)$ of the quinoxalinone core ring $\left(\mathrm{CFTR}_{\text {act }}-\mathrm{J} 105,-\mathrm{J} 135,-\mathrm{J} 136\right)$ gave similar or slightly reduced activity compare to $\mathrm{CFTR}_{\text {act }}-\mathrm{J} 027$, and modifying $\mathrm{R}^{2}$ to a methyl 
substituent was tolerated $\left(\mathrm{CFTR}_{\mathrm{act}} \mathrm{-J} 141\right)$. Changing the 5-nitro on the phenyl ring of the phenylquinoxalinone to a 5-fluoro, 5-bromo or 5-iodo slightly reduced activity (for example, compare $\mathrm{CFTR}_{\text {act-}}-\mathrm{J} 134$ to -J027), while shifting to the 6-position (compare CFTR ${ }_{\text {act }}-\mathrm{J} 134$ to -J142) greatly reduced activity. CFTR act $^{-} \mathrm{J} 135$, the most potent synthesized analog, fully activated CFTR (Fig. 1D), as the cAMP agonist forskolin produced minimal further increase in current, with $\mathrm{EC}_{50} \sim 300 \mathrm{nM}$, which was

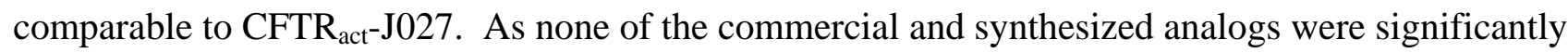
more potent than $\mathrm{CFTR}_{\text {act }} \mathrm{J}$ 027, which was already shown to have favorable pharmacological properties and efficacy in mice (12), subsequent studies were done with CFTR act- $^{-} 027$.

\section{Patch-clamp electrophysiology shows direct CFTR activation by CFTR act J027 $^{-}$}

Patch-clamp was done to investigate the mechanism of CFTR activation by $\mathrm{CFTR}_{\mathrm{act}^{-}} \mathrm{J027}$. In whole-cell recordings CFTR was partially activated using a low concentration of forskolin (150 nM) to give $\sim 25 \%$ maximal stimulation. Addition of $1 \mu \mathrm{M} \mathrm{CFTR}_{\text {act }} \mathrm{J}^{-} 027$ in the extracellular condition further increased CFTR activity by more than four-fold (Fig. 2A-C). The currents activated by forskolin and $\mathrm{CFTR}_{\text {act }}-\mathrm{J} 027$ changed linearly with applied voltage and were blocked by $10 \mu \mathrm{M} \mathrm{CFTR}_{\text {inh }^{-}}-172$. CFTR activation was also measured under cell-free conditions using the inside-out patch-clamp configuration using large pipette tips in order to obtain macropatches containing multiple CFTR channels. After inducing phosphorylation with submaximal ATP and the catalytic subunit of protein kinase A, CFTR act $^{-}$ J027 strongly increased CFTR activity (Fig. 2D). CFTR act $^{-}$J027 thus activates CFTR by a direct binding mechanism, which is consistent with prior data showing that $\mathrm{CFTR}_{\mathrm{act}} \mathrm{J} 027$ does not elevate cellular cAMP concentration (12). 


\section{CFTR $_{\text {act }}$ J027 efficacy in a scopolamine-induced mouse model of acute constipation}

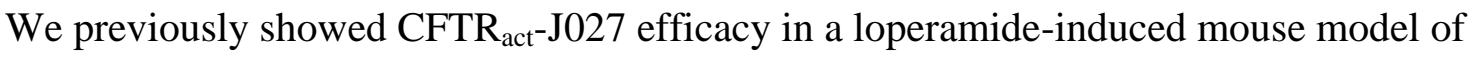
constipation (12). To show efficacy in an alternative, non-opioid mouse model of acute constipation,

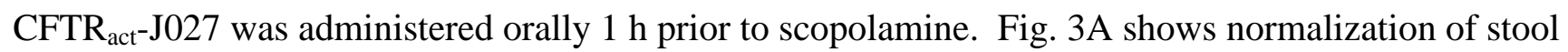
parameters by CFTR $_{\text {act }}$-J027 in the scopolamine-treated mice. CFTR act $^{-}$O27 was also effective when administered intraperitonally after development of constipation in both loperamide and scopolamine models (Fig. 3B). However, CFTR act $^{-J 027}$ was not effective when given orally after development of constipation (Fig. 3C), which is not unexpected as both scopolamine and loperamide delay gastric emptying and intestinal transit, likely preventing CFTR $_{\text {act }}{ }^{-} \mathrm{J} 027$ delivery to its site of action.

\section{CFTR $_{\text {act }}$ J027 efficacy in a genetic mouse model of chronic constipation}

$\mathrm{CFTR}_{\text {act }}-\mathrm{J} 027$ was also tested in a genetic mouse model $(\mathrm{C} 3 \mathrm{H} / \mathrm{HeJ})$ of chronic constipation. $\mathrm{C} 3 \mathrm{H} / \mathrm{HeJ}$ mice have a spontaneous mutation in Toll-like receptor 4 gene $\left(T l r 4^{l p s-d}\right)$, which causes impaired interactions between gut microbiota and enteric neurons resulting in reduced enteric neuronal survival with delayed intestinal transit and decreased stool output (15). We found that $\mathrm{C} 3 \mathrm{H} / \mathrm{HeJ}$ mice have $\sim 30 \%$ reduced stool output compared to control mice in a matched background $(\mathrm{C} 3 \mathrm{H} / \mathrm{HeOuJ})$, with remarkably decreased stool water content and prolonged whole-gut transit time. Oral administration of $10 \mathrm{mg} / \mathrm{kg} \mathrm{CFTR}$ act $^{-J} 027$ increased 4-h stool weight, pellet number and water content in $\mathrm{C} 3 \mathrm{H} / \mathrm{HeJ}$ mice to the level of wildtype controls (Fig. 4A). CFTR $_{\text {act }}-\mathrm{J} 027$ normalized the increased whole-gut transit time in $\mathrm{C} 3 \mathrm{H} / \mathrm{HeJ}$ mice (Fig. 4B), but did not affect stool parameters or whole-gut transit time in the wildtype control mice. 
CFTR $_{\text {act }}$ J027 is stable in gastric acid and rapidly metabolized by human hepatic microsomes

Incubation of $10 \mu \mathrm{M} \mathrm{CFTR}_{\text {act }}-\mathrm{J} 027$ in simulated gastric fluid (pH 2) at $37{ }^{\circ} \mathrm{C}$ for $3 \mathrm{~h}$ showed no compound degradation (Fig. 5A). In vitro metabolic stability measurements in human hepatic microsomes revealed rapid compound metabolism (elimination half-life $\sim 35 \mathrm{~min}$ ), with only $34 \%$ of the compound remaining at $60 \mathrm{~min}$ (Fig. 5B).

Greater efficacy of CFTR act-J027 compared to lubiprostone and linaclotide in increasing intestinal secretion and normalizing stool parameters in constipation

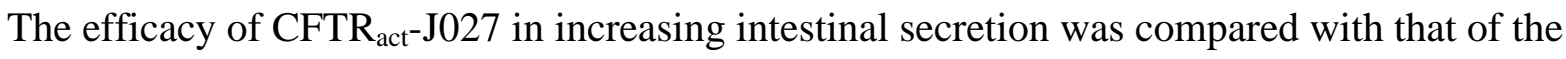
approved prosecretory drugs lubiprostone and linaclotide. In a first set of studies, intestinal fluid accumulation was measured in a closed intestinal loop model. Closed mid-jejunal loops were injected with $\mathrm{CFTR}_{\mathrm{act}}{ }^{-J 027}$ or test drug, and fluid accumulation was quantified after $90 \mathrm{~min}$. Significantly greater intestinal fluid accumulation was produced by $\mathrm{CFTR}_{\text {act }}-\mathrm{J} 027$ compared to equal doses of lubiprostone or linaclotide (Fig. 6A). In a second set of studies, drug efficacy was compared in a mouse model of scopolamine-induced constipation. CFTR $_{\text {act }} \mathrm{J} 027$ was more effective in increasing stool output, pellet number and water content compared to supramaximal (250-500 fold greater than human mg/kg dose) doses of lubiprostone and linaclotide (Fig. 6B).

CFTR $_{\text {act }}$ J027 increases fluid secretion in enteroids generated from normal human duodenum and jejunum

To study CFTR act $^{-} \mathrm{J} 027$ efficacy in a model system of direct relevance to human intestine, swelling responses were measured in enteroids generated from normal human duodenum and jejunum. The 
enteroids comprise a sealed epithelial layer of enterocytes with CFTR expressed at the inner, luminal membrane, in which CFTR activation produces a swelling response over tens of minutes $(16,17)$. Enteroids generated from human duodenum and jejunum showed a slow swelling response to 0.1 or 0.2 $\mu \mathrm{M}$ forskolin (Fig. 7), which was increased by pretreatment for $10 \mathrm{~min}$ with $\mathrm{CFTR}_{\mathrm{act}} \mathrm{J}^{\mathrm{J} 027}$, with greatest effect seen for enteroids from jejunum. The response produced by $\mathrm{CFTR}_{\text {act }}-\mathrm{J} 027$ was approximately $50 \%$ of that produced by maximal $(5 \mu \mathrm{M})$ forskolin.

\section{DISCUSSION}

$\mathrm{CFTR}_{\text {act }}-\mathrm{J} 027$ showed efficacy in rodent models of constipation induced by opioid and non-opioid anti-motility agents, as well as in chronically constipated C3H/HeJ mice. Opioid and non-opioid antimotility agents have been widely used to test laxatives in rodents, as these models are technically simple and informative in short-term studies, and the opioid models have high relevance to OIC in humans. However, they may have limited relevance to human CIC and IBS-C, which are chronic conditions. Genetic models of chronic constipation have more relevance to human CIC and IBS-C due to their chronic phenotype, and do not require pharmacological interventions targeting intestinal motility. Though there are genetically constipated models of Hirschprung's disease with spontaneous mutations in endothelin receptor $B$ (Ednrb) and targeted mutation in Ednrb ligand endothelin 3 that manifest aganglionic colon (18-20), we used $\mathrm{C} 3 \mathrm{H} / \mathrm{HeJ}$ mice here because they manifest chronic constipation but with a milder phenotype and normal survival (15), which make them more relevant to non-life-

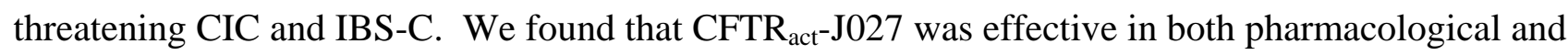
genetic models of constipation, which supports its potential use in acute and various forms of chronic constipation in humans including CIC, IBS-C and OIC. 
A modular approach was developed for efficient synthesis of phenylquinoxalinone analogs using substituted nitro-anilines, benzyl bromides and isatins. The most potent phenylquinoxalinones have favorable drug-like properties, including the presence of multiple hydrogen bond acceptors, average molecular weight of $\sim 400 \mathrm{Da}$, aLogP of $\sim 4.0$ and topological polar surface areas of $\sim 80 \AA^{2}(21,22)$.

Patch-clamp studies indicated direct activation of CFTR by CFTR $_{\text {act }}-$ J027. CFTR activation by $\mathrm{CFTR}_{\text {act }}-\mathrm{J} 027$ required a low level of phosphorylation, as produced by submaximal forskolin in wholecell recordings and ATP/catalytic subunit of protein kinase A in inside-out patches, and by a low concentration of forskolin in enteroid swelling measurements. Basal CFTR phosphorylation is required as well for other CFTR activators, including the clinically approved compound VX-770, a potentiator of some mutant CFTRs causing cystic fibrosis (23). The current-voltage relationship in cells stimulated

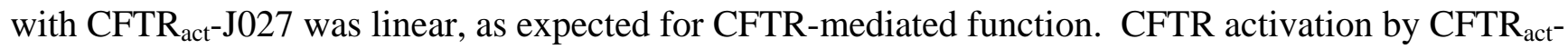
J027 in inside-out patches indicates a direct activation mechanism, likely at a site on the cytoplasmic domain of CFTR. Further studies are needed by define the precise binding site of CFTR act $^{-J 027 ~ o n ~}$ CFTR, which are likely to be quite challenging because of the large size of CFTR and its complex gating mechanism. Indeed, the site of action of clinically approved potentiators and correctors of mutant CFTRs causing cystic fibrosis is not known.

We found greater effect of $\mathrm{CFTR}_{\mathrm{act}}-\mathrm{J} 027$ compared with lubiprostone or linaclotide in stimulating fluid secretion in mouse intestine, which translated to greater efficacy in increasing stool output and hydration in a scopolamine model of constipation. The greater efficacy of $\mathrm{CFTR}_{\mathrm{act}}-\mathrm{J} 027$ may be due to greater intestinal secretion. Lubiprostone and linaclotide are thought to act largely by inducing intestinal fluid secretion, though by different mechanisms. These compounds activate intestinal secretory pathways indirectly by increasing cellular cyclic nucleotide levels through their actions on prostanoid and guanylate cyclase $\mathrm{C}$ receptors, respectively $(3,5)$. The non-selective activation of cyclic nucleotide 
pathways may be responsible in part for the side effects of these drugs. Compared to lubiprostone and linaclotide, direct-acting CFTR activators have a defined mechanism of action targeting a single prosecretory ion transporter, with less likelihood of side effects due to absence of global cyclic nucleotide elevation (24). Also, targeting CFTR directly rather than upstream receptor or signaling pathways is less likely to induce tachyphylaxis. Whether the greater therapeutic action of $\mathrm{CFTR}_{\mathrm{act}}-\mathrm{J} 027$ compared with lubiprostone or linaclotide seen here in mice will translate to humans must await clinical trial data.

The preclinical results here support the testing of $\mathrm{CFTR}_{\text {act }}-\mathrm{J} 027$ or alternative CFTR-targeted activators in constipation in humans. We previously reported an $\mathrm{ED}_{50}$ of $0.5 \mathrm{mg} / \mathrm{kg}$ for orally administered CFTR $_{\text {act }}-\mathrm{J} 027$ in a loperamide model in mice, which translates to a dose of $35 \mathrm{mg}$ for a 70 $\mathrm{kg}$ human. The duration of effect for $\mathrm{CFTR}_{\mathrm{act}}{ }^{-\mathrm{J} 027}$ is at least 3-4 h in mice, suggesting that a once a day administration may be adequate for treatment of constipation in humans. Pharmacology studies in mice (12) and the rapid metabolism found here with human hepatic microsomes ( $\left.\mathrm{t}_{1 / 2} 35 \mathrm{~min}\right)$ predict minimal systemic exposure following oral administration of $\mathrm{CFTR}_{\mathrm{act}}-\mathrm{J}_{027}$ because of rapid hepatic metabolism probably by a first-pass mechanism, though formal pharmacokinetics measurements will be needed in humans. The minimal systemic exposure is expected to limit the extraintestinal off-target effects of $\mathrm{CFTR}_{\text {act-}}{ }^{-J 027}$, as evidenced by our prior toxicity studies in mice showing no effect of chronic oral highdose CFTR act- $^{-} 027$ on blood counts, serum chemistries and lung water content (12). A potential side effect of any laxative is diarrhea, which might occur with CFTR $_{\text {act }^{-}} \mathrm{J} 027$ in a dose-dependent manner and require appropriate dose adjustment.

In conclusion, our results show that a CFTR-targeted small molecule increases intestinal fluid secretion and is efficacious orally in mouse models of acute and chronic constipation. CFTR $_{\text {act }}{ }^{-J 027}$ induced enterocyte fluid secretion in human enteroids and showed rapid metabolism in human hepatic microsomes, supporting its utility for human constipation. 
Acknowledgments. This work was supported by grants DK099803, DK72517, DK101373,

DK35124, EB00415, EY13574, DK26523, DK61765, DK089502, TR000552, TR000504 and TR000504 from the National Institutes of Health (NIH), a Research Development Program grant from the Cystic Fibrosis Foundation, a Catalyst grant from funds awarded to the UCSF CTSI (UL1 TR000004), a Gates Foundation Grand Challenges Grant and grants from Ministero della Salute (Ricerca Corrente: Cinque per mille). All authors have read the journal's authorship agreement and policy on disclosure of potential conflicts of interest.

Disclosures: OC and ASV are named inventors on provisional patent filings, with rights owned by the University of California, San Francisco. The other authors have nothing to declare. 
Table 1. CFTR activation by phenylquinoxalinone analogs.

\begin{tabular}{|c|c|c|c|c|c|}
\hline Compound & $\mathbf{R}^{1}$ & $\mathbf{R}^{2}$ & $\mathbf{R}^{3}$ & $\mathbf{R}^{4}$ & $\mathrm{EC}_{50}(\mu \mathrm{M})$ \\
\hline $\mathrm{CFTR}_{\mathrm{act}^{-}}{ }^{\mathrm{J} 027}$ & $\mathrm{Bn}$ & $\mathrm{H}$ & $\mathrm{NH}_{2}$ & $5-\mathrm{NO}_{2}$ & 0.2 \\
\hline CFTR $_{\text {act }^{-}}{ }^{-J 051}$ & $\mathrm{H}$ & $\mathrm{H}$ & $\mathrm{NH}_{2}$ & $5-\mathrm{NO}_{2}$ & $>25$ \\
\hline $\mathrm{CFTR}_{\mathrm{act}^{-}}{ }^{\mathrm{J} 052}$ & $\mathrm{CH}_{3}$ & $\mathrm{H}$ & $\mathrm{NH}_{2}$ & $5-\mathrm{NO}_{2}$ & $\sim 10$ \\
\hline CFTR $_{\text {act }}{ }^{-J 053}$ & $\mathrm{CH}_{3}$ & $\mathrm{H}$ & $\mathrm{NH}_{2}$ & $\mathrm{H}$ & $>25$ \\
\hline $\mathrm{CFTR}_{\mathrm{act}^{-}}{ }^{\mathrm{J} 054}$ & $\mathrm{CH}_{3}$ & $\mathrm{NO}_{2}$ & $\mathrm{NH}_{2}$ & $5-\mathrm{NO}_{2}$ & $\sim 10$ \\
\hline $\mathrm{CFTR}_{\mathrm{act}^{-}}{ }^{\mathrm{J} 055}$ & $\mathrm{CH}_{3}$ & $\mathrm{NO}_{2}$ & NHMe & $5-\mathrm{NO}_{2}$ & $>25$ \\
\hline $\mathrm{CFTR}_{\mathrm{act}^{-}}{ }^{\mathrm{J} 056}$ & $\mathrm{Bn}$ & $\mathrm{H}$ & NHBn & $5-\mathrm{Br}$ & $\sim 15$ \\
\hline $\mathrm{CFTR}_{\mathrm{act}^{-}}{ }^{\mathrm{J} 057}$ & $\mathrm{Bn}$ & $\mathrm{H}$ & NHAc & $\mathrm{H}$ & $\sim 15$ \\
\hline CFTR $_{\text {act }^{-}}{ }^{-J 058}$ & phenylacetyl & $\mathrm{H}$ & NHAc & $\mathrm{H}$ & $\sim 20$ \\
\hline CFTR $_{\text {act }^{-}}{ }^{-} 059$ & 3-BrBn & $\mathrm{H}$ & NHAc & $\mathrm{H}$ & $\sim 19$ \\
\hline $\mathrm{CFTR}_{\mathrm{act}^{-}}{ }^{\mathrm{J} 060}$ & $\mathrm{Bn}$ & $\mathrm{H}$ & NHAc & $5-\mathrm{CH}_{3}$ & $>25$ \\
\hline CFTR $_{\text {act }^{-}{ }^{-J 061}}$ & phenethyl & $\mathrm{H}$ & NHAc & $\mathrm{H}$ & $\sim 20$ \\
\hline $\mathrm{CFTR}_{\mathrm{act}^{-}}{ }^{\mathrm{J} 062}$ & $n$-propyl & $\mathrm{H}$ & $\mathrm{H}$ & 5-NHAc & $>25$ \\
\hline $\mathrm{CFTR}_{\mathrm{act}^{-}} \mathrm{J} 102$ & 4-BrBn & $\mathrm{H}$ & $\mathrm{NH}_{2}$ & $5-\mathrm{NO}_{2}$ & $>25$ \\
\hline CFTR $_{\text {act }^{-}}{ }^{-J 103}$ & 3-BrBn & $\mathrm{H}$ & $\mathrm{NH}_{2}$ & $5-\mathrm{NO}_{2}$ & 1.2 \\
\hline CFTR $_{\text {act }^{-}}{ }^{-J 104}$ & 2-BrBn & $\mathrm{H}$ & $\mathrm{NH}_{2}$ & $5-\mathrm{NO}_{2}$ & 7.3 \\
\hline CFTR $_{\text {act }}{ }^{-J 109}$ & $\mathrm{Bn}$ & $\mathrm{H}$ & NHAc & $5-\mathrm{NO}_{2}$ & 1.5 \\
\hline CFTR $_{\text {act }^{-}} \mathrm{J} 105$ & $\mathrm{Bn}$ & $\mathrm{F}$ & $\mathrm{NH}_{2}$ & $5-\mathrm{NO}_{2}$ & 0.53 \\
\hline CFTR $_{\text {act }^{-}}{ }^{-} 135$ & $\mathrm{Bn}$ & $\mathrm{Cl}$ & $\mathrm{NH}_{2}$ & $5-\mathrm{NO}_{2}$ & 0.11 \\
\hline CFTR $_{\text {act }^{-}}{ }^{-J 136}$ & $\mathrm{Bn}$ & $\mathrm{Br}$ & $\mathrm{NH}_{2}$ & $5-\mathrm{NO}_{2}$ & 0.26 \\
\hline CFTR $_{\text {act }^{-}}{ }^{-J 133}$ & $\mathrm{Bn}$ & $\mathrm{H}$ & $\mathrm{NH}_{2}$ & $5-\mathrm{F}$ & 0.79 \\
\hline CFTR $_{\text {act }^{-}}{ }^{-J 134}$ & $\mathrm{Bn}$ & $\mathrm{H}$ & $\mathrm{NH}_{2}$ & $5-\mathrm{Br}$ & 0.31 \\
\hline $\mathrm{CFTR}_{\mathrm{act}^{-}} \mathrm{J} 140$ & $\mathrm{Bn}$ & $\mathrm{CH}_{3}$ & $\mathrm{NH}_{2}$ & $5-\mathrm{F}$ & 0.70 \\
\hline CFTR $_{\text {act }^{-}} \mathrm{J} 141$ & $\mathrm{Bn}$ & $\mathrm{CH}_{3}$ & $\mathrm{NH}_{2}$ & $5-\mathrm{I}$ & 0.47 \\
\hline CFTR $_{\text {act }^{-}}{ }^{-J 143}$ & $2-\mathrm{NO}_{2} \mathrm{Bn}$ & $\mathrm{H}$ & $\mathrm{NH}_{2}$ & $5-\mathrm{I}$ & $>25$ \\
\hline CFTR $_{\text {act }^{-}}{ }^{-J 144}$ & 2-CNBn & $\mathrm{H}$ & $\mathrm{NH}_{2}$ & $5-\mathrm{I}$ & $>25$ \\
\hline CFTR $_{\text {act }^{-}}{ }^{-} 142$ & $\mathrm{Bn}$ & $\mathrm{H}$ & $\mathrm{NH}_{2}$ & $6-\mathrm{Br}$ & 1.5 \\
\hline CFTR $_{\text {act }^{-}}{ }^{-J 139}$ & $\mathrm{Bn}$ & $\mathrm{CH}_{3}$ & $\mathrm{NH}_{2}$ & $6-\mathrm{Br}$ & 0.65 \\
\hline
\end{tabular}

Approximate $\mathrm{EC}_{50}$ of commercial analogs $\left(\mathrm{CFTR}_{\mathrm{act}}-\mathrm{J} 051\right.$ - J062) deduced from twoconcentration point analysis. $\mathrm{EC}_{50}$ of synthesized compounds measured from full dose-response study. 


\section{REFERENCES}

1. Pinto Sanchez MI, Bercik P. Epidemiology and burden of chronic constipation. Canadian Journal of Gastroenterology. 2011;25(Suppl B):11B-5B.

2. Menees S, Saad R, Chey WD. Agents that act luminally to treat diarrhoea and constipation. Nature Reviews Gastroenterology Hepatology. 2012;9(11):661-74.

3. Castro J, Harrington AM, Hughes PA, Martin CM, Ge P, Shea CM, et al. Linaclotide Inhibits Colonic Nociceptors and Relieves Abdominal Pain via Guanylate Cyclase-C and Extracellular Cyclic Guanosine 3',5'-Monophosphate. Gastroenterology. 2013;145(6):1334-46.e11.

4. Fei G, Raehal K, Liu S, Qu M-H, Sun X, Wang G-D, et al. Lubiprostone Reverses the Inhibitory Action of Morphine on Intestinal Secretion in Guinea Pig and Mouse. Journal of Pharmacology and Experimental Therapeutics. 2010;334(1):333-40.

5. Bijvelds MJC, Bot AGM, Escher JC, de Jonge HR. Activation of Intestinal $\mathrm{Cl}^{-}$Secretion by Lubiprostone Requires the Cystic Fibrosis Transmembrane Conductance Regulator. Gastroenterology. 2009;137(3):976-85.

6. Chey WD, Webster L, Sostek M, Lappalainen J, Barker PN, Tack J. Naloxegol for OpioidInduced Constipation in Patients with Noncancer Pain. New England Journal of Medicine. 2014;370(25):2387-96.

7. www.amitizahcp.com (Access date: June 2016)

8. www.linzesshcp.com (Access date: June 2016)

9. www.movantikhcp.com (Access date: June 2016)

10. Field M, Fromm D, Al-Awqati Q, Greenough WB, III. Effect of Cholera Enterotoxin on Ion Transport across Isolated Ileal Mucosa. The Journal of Clinical Investigation. 1972;51(4):796804. 
11. Rao MC, Guandalini S, Smith PL, Field M. Mode of Action of Heat-stable Escherichia coli Enterotoxin Tissue and Subcellular Specificities and Role of Cyclic GMP. Biochimica et Biophysica Acta (BBA) - General Subjects. 1980;632(1):35-46.

12. Cil O, Phuan PW, Lee S, Tan J, Haggie PM, Levin MH, et al. CFTR Activator Increases Intestinal Fluid Secretion and Normalizes Stool Output in a Mouse Model of Constipation. Cellular and Molecular Gastroenterology and Hepatology. 2(3):317-27.

13. Ma T, Vetrivel L, Yang H, Pedemonte N, Zegarra-Moran O, Galietta LJV, et al. High-affinity Activators of Cystic Fibrosis Transmembrane Conductance Regulator (CFTR) Chloride Conductance Identified by High-throughput Screening. Journal of Biological Chemistry. 2002;277(40):37235-41.

14. Galietta LJV, Springsteel MF, Eda M, Niedzinski EJ, By K, Haddadin MJ, et al. Novel CFTR Chloride Channel Activators Identified by Screening of Combinatorial Libraries Based on Flavone and Benzoquinolizinium Lead Compounds. Journal of Biological Chemistry. 2001;276(23):19723-8.

15. Anitha M, Vijay-Kumar M, Sitaraman SV, Gewirtz AT, Srinivasan S. Gut Microbial Products Regulate Murine Gastrointestinal Motility via Toll-Like Receptor 4 Signaling. Gastroenterology. 2012;143(4):1006-16.e4.

16. Foulke-Abel J, In J, Yin J, Zachos NC, Kovbasnjuk O, Estes MK, et al. Human Enteroids as a Model of Upper Small Intestinal Ion Transport Physiology and Pathophysiology. Gastroenterology. 2016;150(3):638-49.e8.

17. Dekkers JF, Wiegerinck CL, de Jonge HR, Bronsveld I, Janssens HM, de Winter-de Groot KM, et al. A Functional CFTR Assay using Primary Cystic Fibrosis Intestinal Organoids. Nature Medicine. 2013;19(7):939-45. 
18. Webster W. Embryogenesis of the Enteric Ganglia in Normal Mice and in Mice that Develop Congenital Aganglionic Megacolon. Development. 1973;30(3):573-85.

19. Hosoda K, Hammer RE, Richardson JA, Baynash AG, Cheung JC, Giaid A, et al. Targeted and Natural (Piebald-lethal) Mutations of Endothelin-B Receptor Gene Produce Megacolon Associated with Spotted Coat Color in Mice. Cell. 1994;79(7):1267-76.

20. Zarate N, Spencer NJ. Chronic constipation: Lessons from Animal Studies. Best Practice \& Research Clinical Gastroenterology. 2011;25(1):59-71.

21. Lipinski CA, Lombardo F, Dominy BW, Feeney PJ. Experimental and Computational Approaches to Estimate Solubility and Permeability in Drug Discovery and Development Settings. Advanced Drug Delivery Reviews. 2001;46(1-3):3-26.

22. Veber DF, Johnson SR, Cheng H-Y, Smith BR, Ward KW, Kopple KD. Molecular Properties That Influence the Oral Bioavailability of Drug Candidates. Journal of Medicinal Chemistry. 2002;45(12):2615-23.

23. Eckford PDW, Li C, Ramjeesingh M, Bear CE. Cystic Fibrosis Transmembrane Conductance Regulator (CFTR) Potentiator VX-770 (Ivacaftor) Opens the Defective Channel Gate of Mutant CFTR in a Phosphorylation-Dependent but ATP-independent Manner. Journal of Biological Chemistry. 2012;287(44):36639-49.

24. Lencer WI. Opening CFTR in the Intestine: Flushing on Demand. Cellular and Molecular Gastroenterology and Hepatology. 2(3):256. 


\section{FIGURE LEGENDS}

Figure 1. Synthesis and structure-activity analysis of phenylquinoxalinone CFTR activators.
A. General synthetic scheme.
B. Concentration-dependent activation of CFTR by selected phenylquinoxalinones in FRT cells expressing wildtype CFTR (mean \pm S.E.M., $n=3$ ). Dashed line indicates response to $125 \mathrm{nM}$ forskolin. C. Structural determinants of phenylquinoxalinone activation of wildtype CFTR. D. Short-circuit current measurement in FRT cells expressing wildtype CFTR cells showing responses to indicated concentrations of forskolin (fsk), CFTR $\mathrm{act}^{-} \mathrm{J} 135$, and CFTR $_{\text {inh }}-172$ (representative of 3 experiments).

Figure 2. Patch-clamp analysis of CFTR activation by CFTR act-J027. A. Representative wholecell patch-clamp in FRT cells expressing human wildtype CFTR. Each panel shows superimposed membrane currents elicited at voltages between -100 and $+100 \mathrm{mV}$ (with $20 \mathrm{mV}$ steps). Cells were

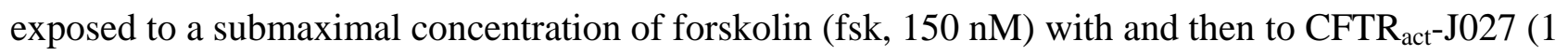

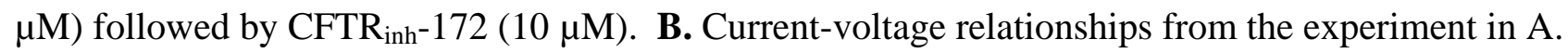
C. Membrane conductance deduced from experiments as in B (mean \pm S.E.M., 4 experiments). D. Currents measured in inside-out patch-clamp experiment. CFTR was activated by submaximal ATP and catalytic subunit of protein kinase A (PKA), followed by CFTR $_{\text {act }^{-}} \mathrm{J} 027(1 \mu \mathrm{M})$. The voltage stimulation protocol was the same used for whole-cell experiments. Data representative of three sets of experiments.

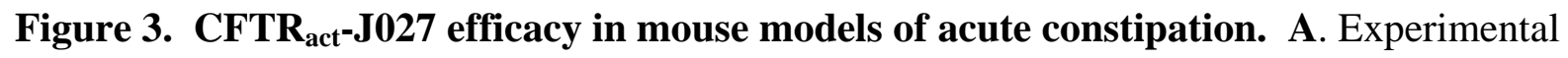
protocol (left) and 3-hour stool weight, pellet number and water content in mice treated with CFTR act- $^{-}$ 
$\mathrm{J} 027(10 \mathrm{mg} / \mathrm{kg}$, po) or vehicle $1 \mathrm{~h}$ before scopolamine $(0.5 \mathrm{mg} / \mathrm{kg}$, ip) (mean \pm S.E.M., 4 mice per group). B. Experimental protocol (left) and 3-hour stool weight and pellet number in mice treated with CFTR act $^{-} \mathrm{J} 027(10 \mathrm{mg} / \mathrm{kg}$, ip) or vehicle $1 \mathrm{~h}$ after scopolamine $(0.5 \mathrm{mg} / \mathrm{kg}$, ip) or loperamide $(0.3$ $\mathrm{mg} / \mathrm{kg}$, ip) (mean \pm S.E.M., 4 mice per group). C. Experimental protocol (left) and 3-hour stool weight and pellet number in mice treated with CFTR act $^{-} \mathrm{J} 027(10 \mathrm{mg} / \mathrm{kg}$, po $)$ or vehicle $1 \mathrm{~h}$ after scopolamine $(0.5 \mathrm{mg} / \mathrm{kg}$, ip) or loperamide $(0.3 \mathrm{mg} / \mathrm{kg}$, ip) (mean \pm S.E.M., 4 mice per group). Oneway analysis of variance was used for $\mathrm{A}$ and $\mathrm{B}$, Student's t-test was used for $\mathrm{C},{ }^{*} \mathrm{P}<0.05, * * \mathrm{P}<0.01$, $* * * \mathrm{P}<0.001$, ns: not significant.

Figure 4. CFTR $_{\text {act }}-\mathrm{J027}$ reverses constipation in chronically constipated $\mathrm{C} 3 \mathrm{H} / \mathrm{HeJ}$ mice.

A. Four-hour stool weight, pellet number and water content (left) and percent change in these parameters after $\mathrm{CFTR}_{\mathrm{act}} \mathrm{J} 027(10 \mathrm{mg} / \mathrm{kg}$, po) or vehicle treatment (center) in $\mathrm{C} 3 \mathrm{H} / \mathrm{HeJ}$ and $\mathrm{C} 3 \mathrm{H} / \mathrm{HeOuJ}$ mice (mean \pm S.E.M., 10 mice per group). Experimental protocol is on top right. B. Whole-gut transit time in $\mathrm{C} 3 \mathrm{H} / \mathrm{HeJ}$ and $\mathrm{C} 3 \mathrm{H} / \mathrm{HeOuJ}$ mice treated with $\mathrm{CFTR}_{\text {act }} \mathrm{J} 027(10 \mathrm{mg} / \mathrm{kg}$, ip) or vehicle at zero time (mean \pm S.E.M., 5 mice per group). Student's t-test, $* \mathrm{P}<0.05, * * \mathrm{P}<0.01$, ***P<0.001, ns: not significant. All experiments were done in paired animals.

Figure 5. CFTR $_{\text {act }}-\mathrm{J027}$ is rapidly metabolized by human liver microsomes and is gastric acidstable. A. In vitro metabolic stability of $\mathrm{CFTR}_{\text {act }} \mathrm{J} 027$ assayed in human liver microsomes in the presence of NADPH after incubation for specified times, with representative chromatograms on the left. B. Stability of CFTR act J027 in simulated gastric fluid (pH 2) after $3 \mathrm{~h}$ incubation, with representative chromatograms on the left (mean \pm S.E.M., $n=3$ ). 


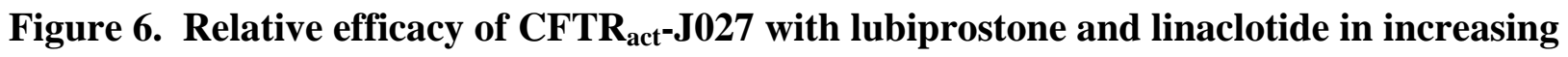
intestinal fluid secretion and stool output. A. Intestinal fluid secretion was measured in closed midjejunal loops in mice. Loops were injected with $100 \mu \mathrm{L}$ vehicle or $100 \mu \mathrm{g} \mathrm{CFTR}_{\mathrm{act}} \mathrm{J}^{-} 027$, lubiprostone or linaclotide. Loop weight/length was measured at $90 \mathrm{~min}$ (mean \pm S.E.M., 4-8 loops per group, representative photos on right). B. Three-hour stool weight, pellet number and water content in mice orally treated with CFTR $_{\text {act- }}{ } 027(10 \mathrm{mg} / \mathrm{kg})$, lubiprostone $(0.5 \mathrm{mg} / \mathrm{kg})$, linaclotide $(0.5 \mathrm{mg} / \mathrm{kg})$ or vehicle in a scopolamine model of constipation as done in Fig. 3A (mean \pm S.E.M., 4 mice per group). One-way analysis of variance, $* \mathrm{P}<0.05, * * \mathrm{P}<0.01, * * * \mathrm{P}<0.001$.

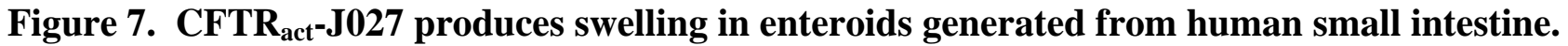
Percentage increase in enteroid area, as deduced by confocal fluorescence microscopy of calceinstained enteroids, relative to initial area. Data shown for enteroids from human jejunum (left) and duodenum (right). Mean \pm S.E.M., $\mathrm{n} \geq 10$ enteroids for each condition. 

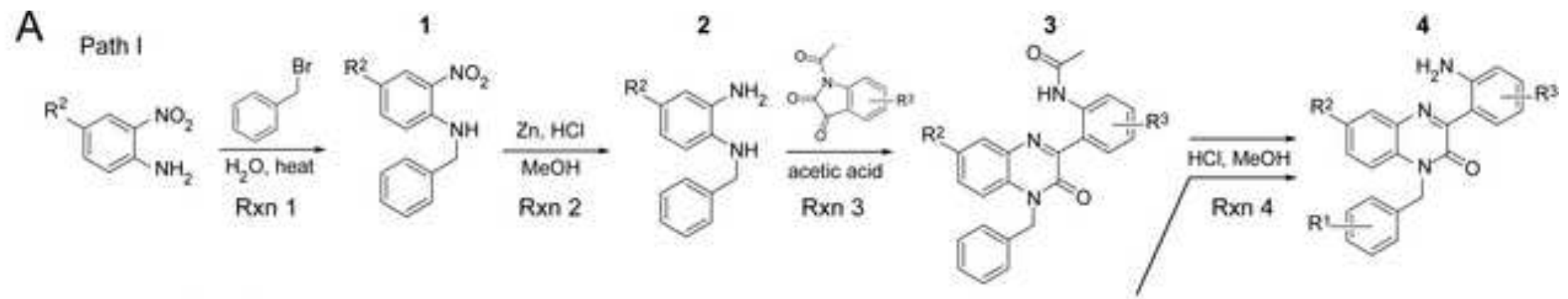

B

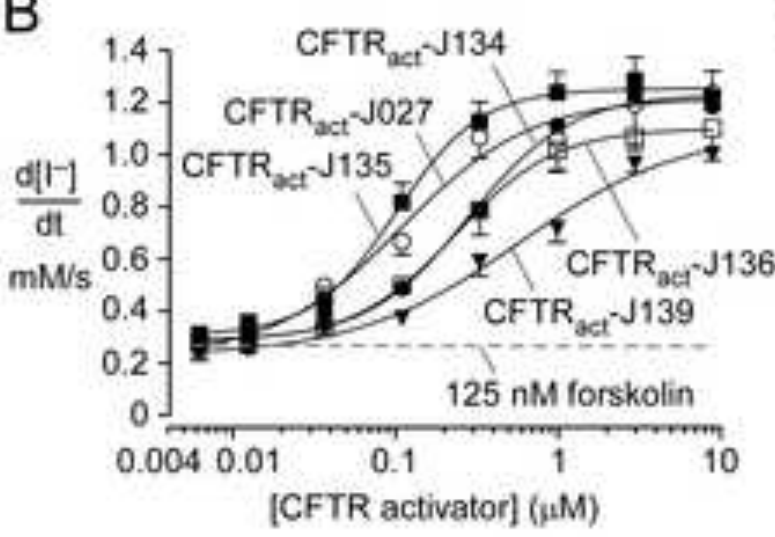

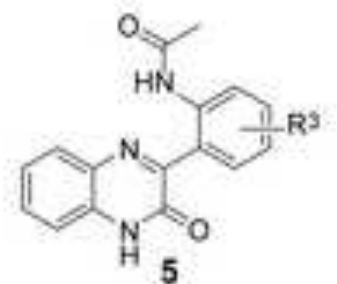

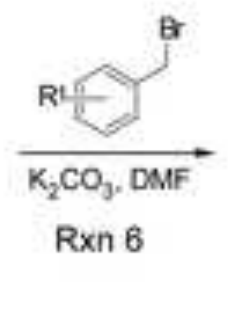

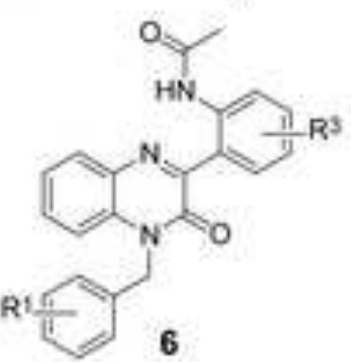

C

best $\mathrm{R}^{2}=\mathrm{H}, \mathrm{Cl}, \mathrm{Br}$ moderate $\mathrm{R}^{2}=\mathrm{F}, \mathrm{CH}_{3}$ inactive $\mathrm{R}^{2}=\mathrm{CF}_{3}$

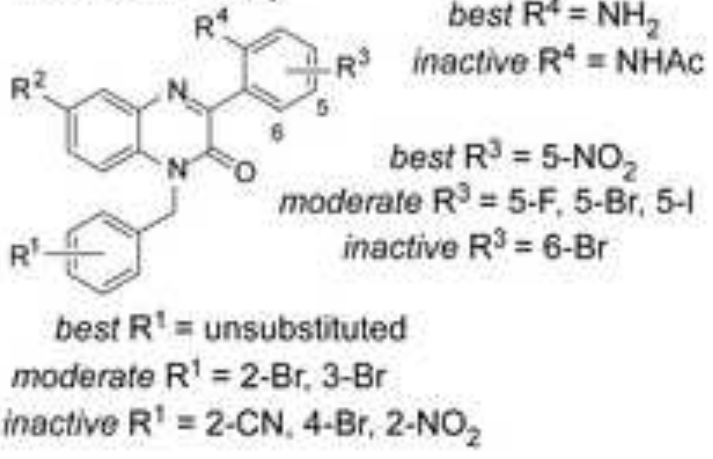

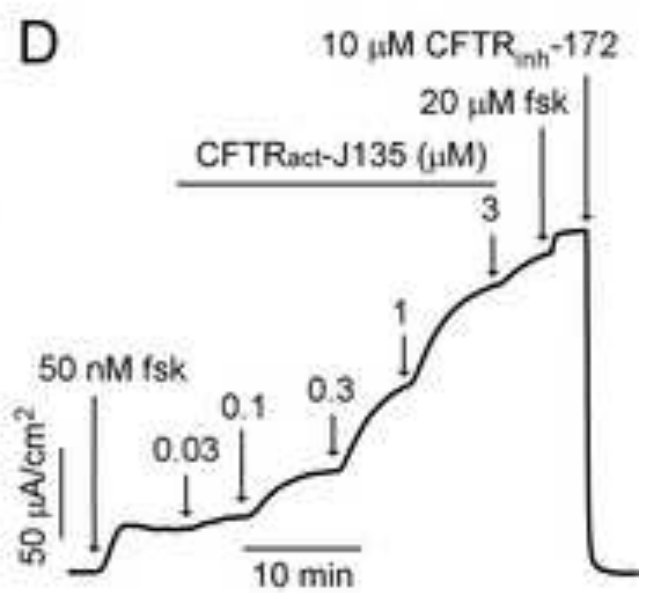

\section{Figure 1}


Figure 2

A

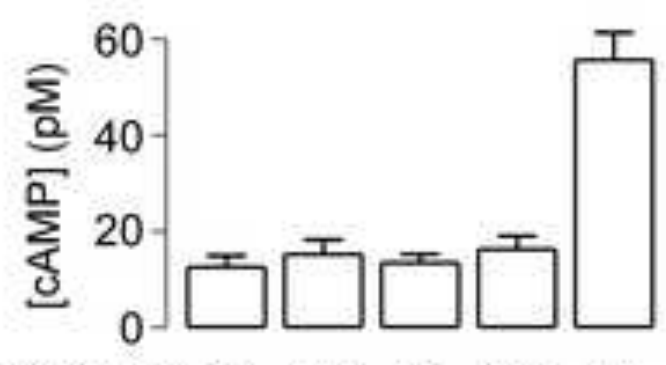

[forskolin] ( $\mu \mathrm{M}) \quad 0 \quad 0.09 \quad 0 \quad 0.09 \quad 20$ CFTR $_{\text {act }}$-J027 - + - + -

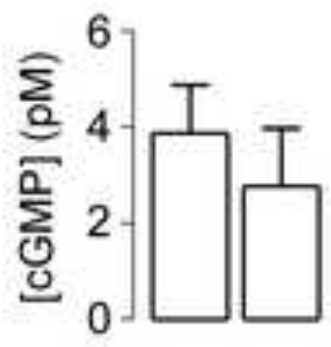

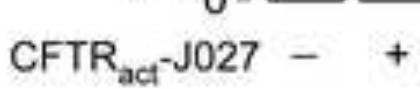

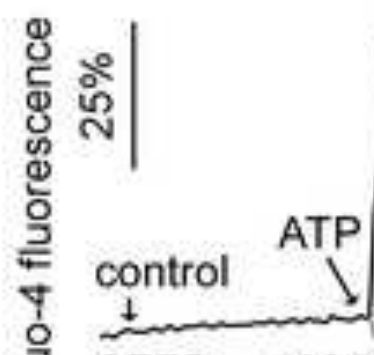

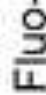

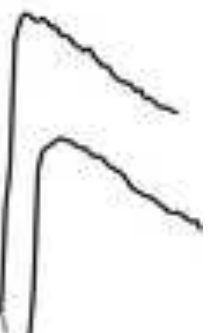

$1 \mathrm{~min}$
B

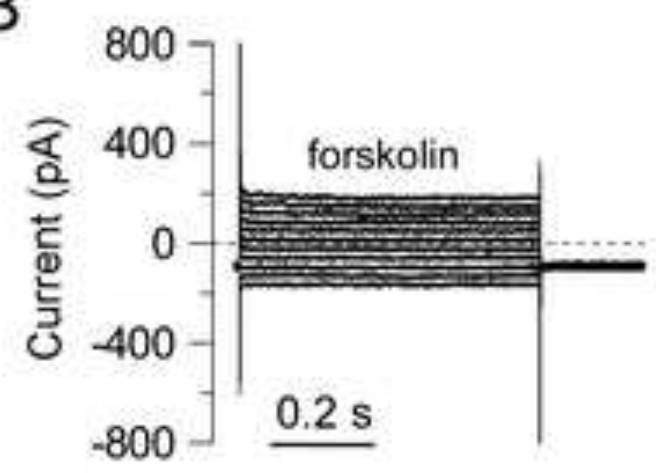

C

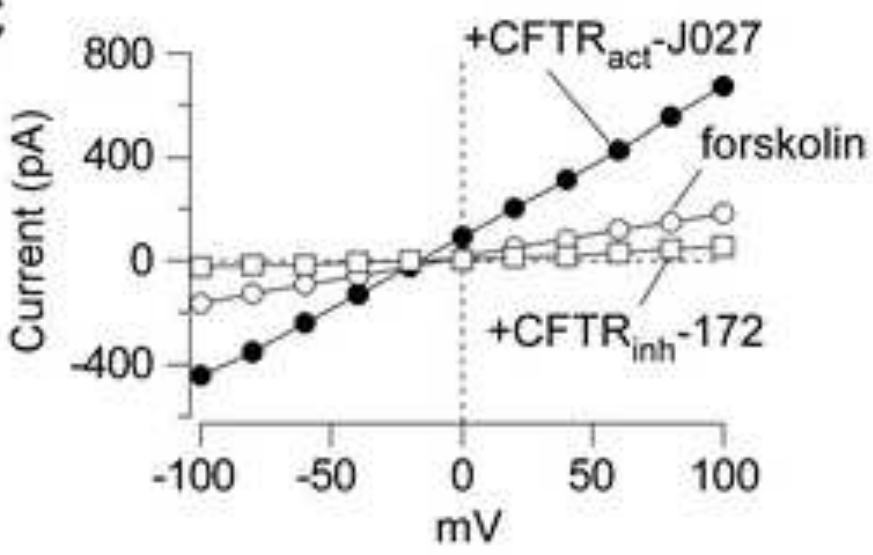

E

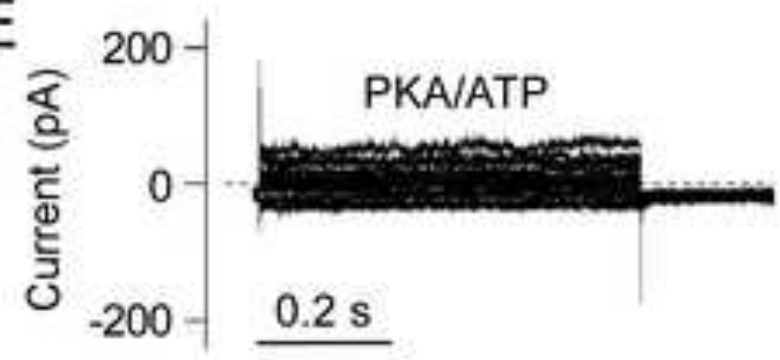

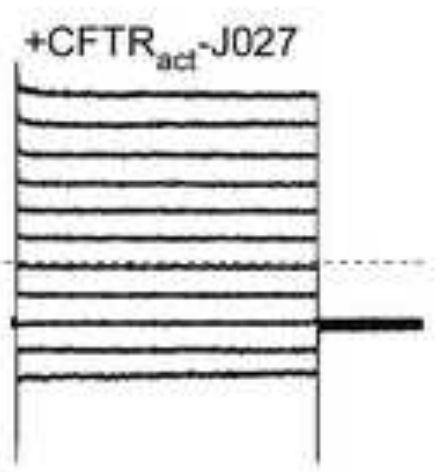
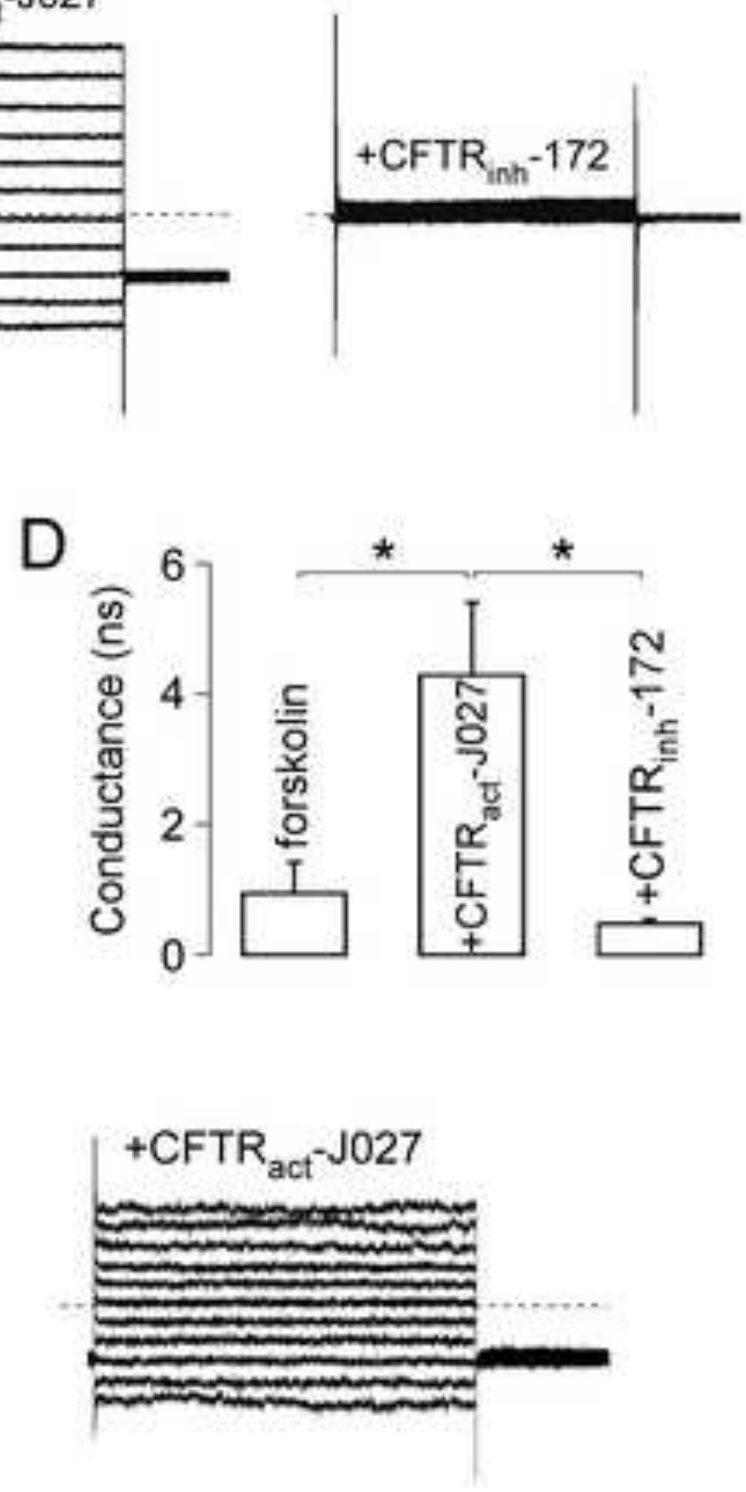

Figure 2 
A

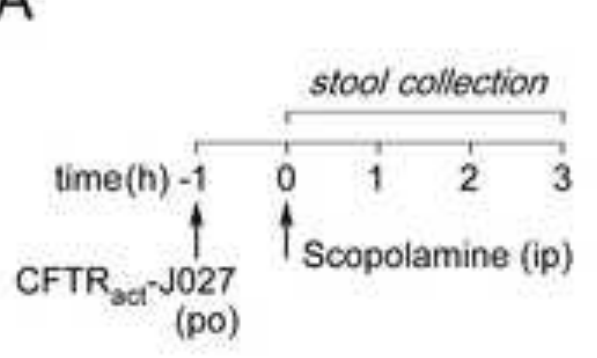

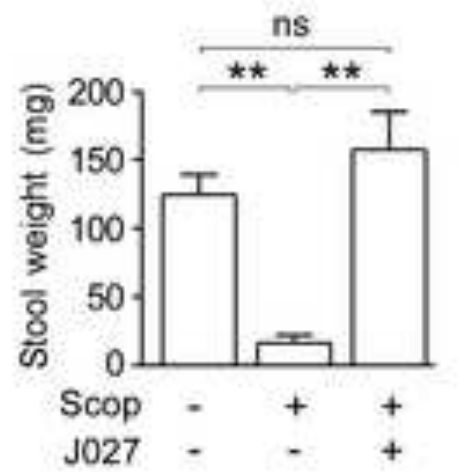
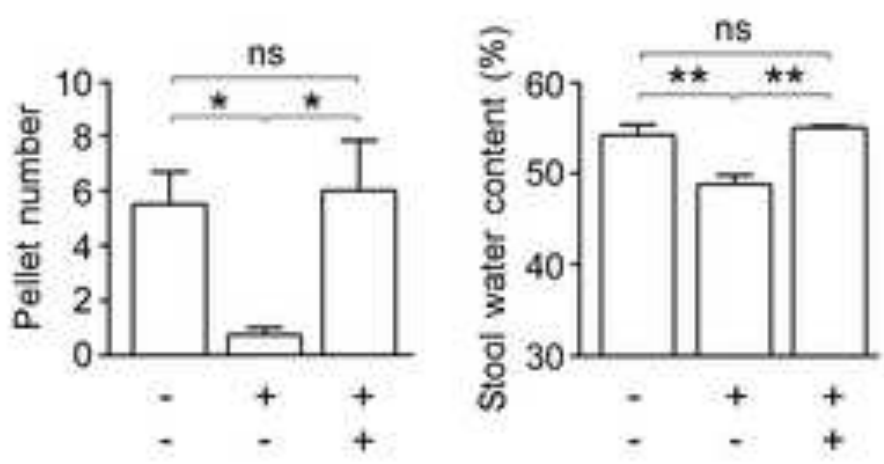

B
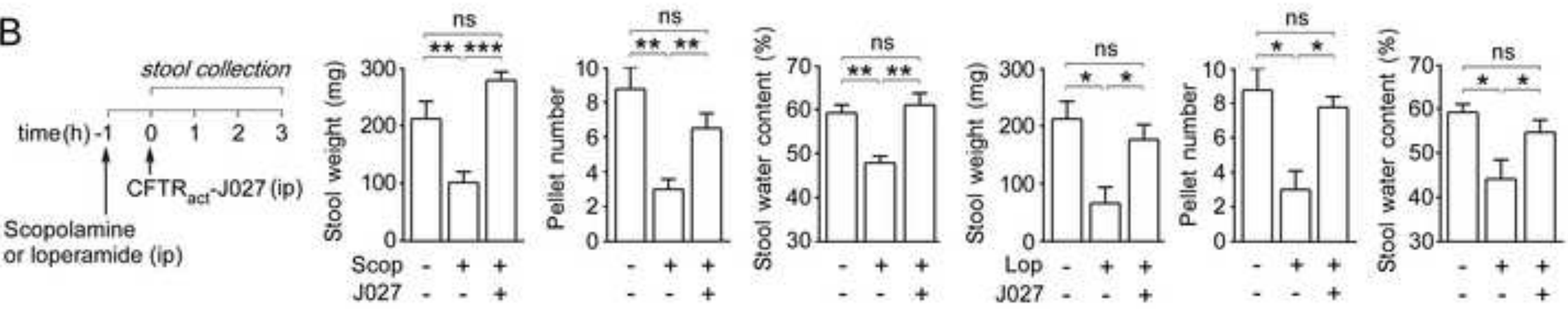

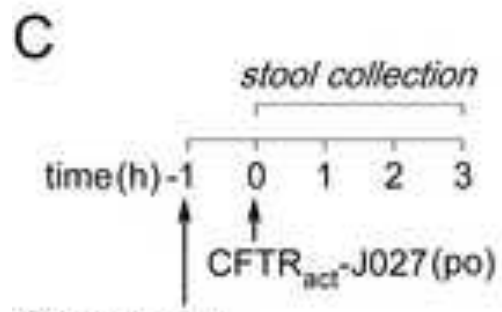

Scopolamine

or loperamide (ip)
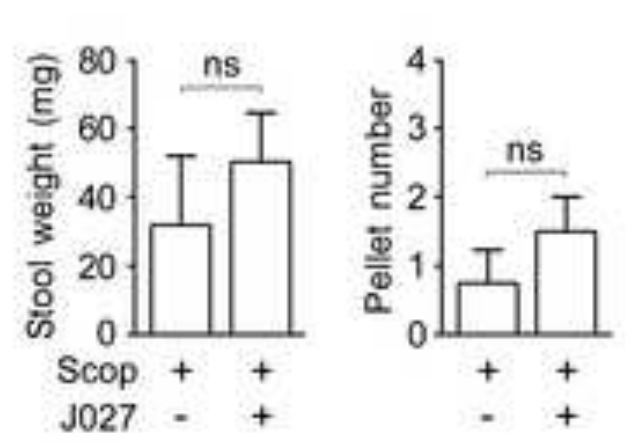

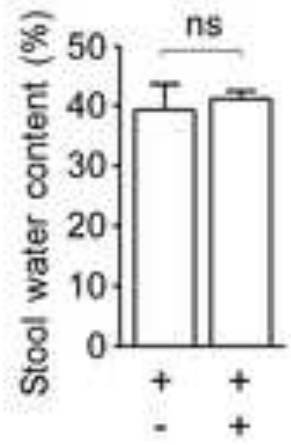

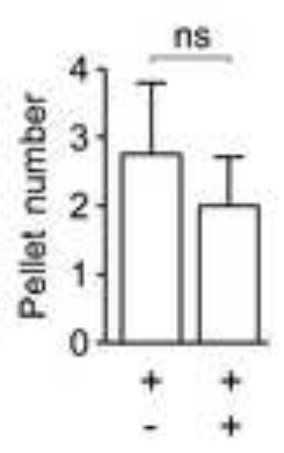

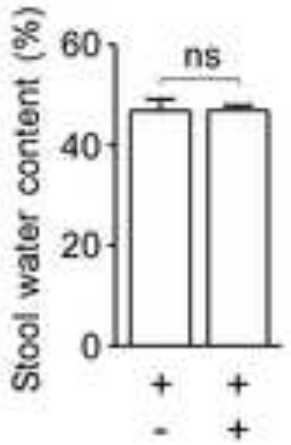

Figure 3 

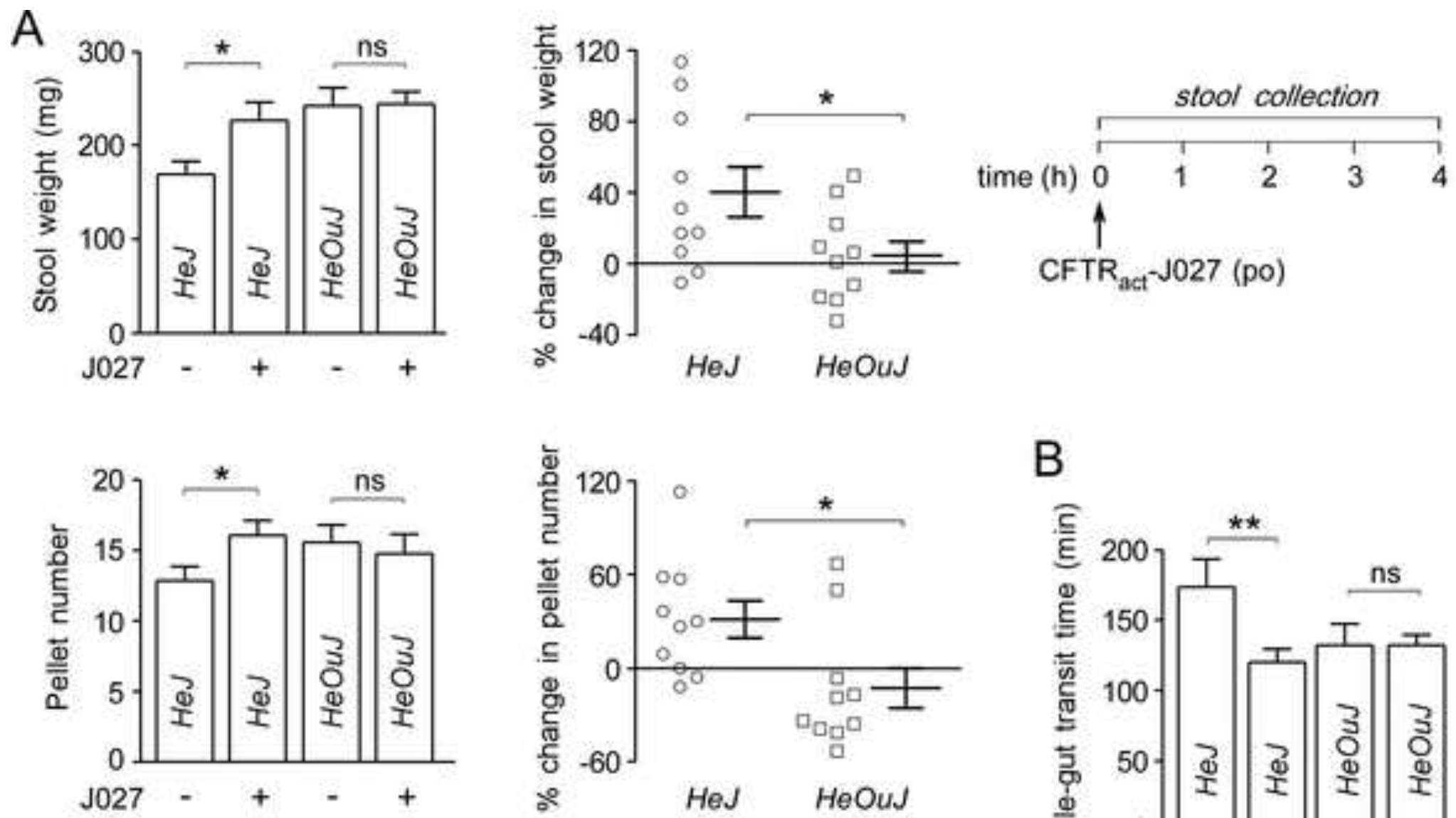

B
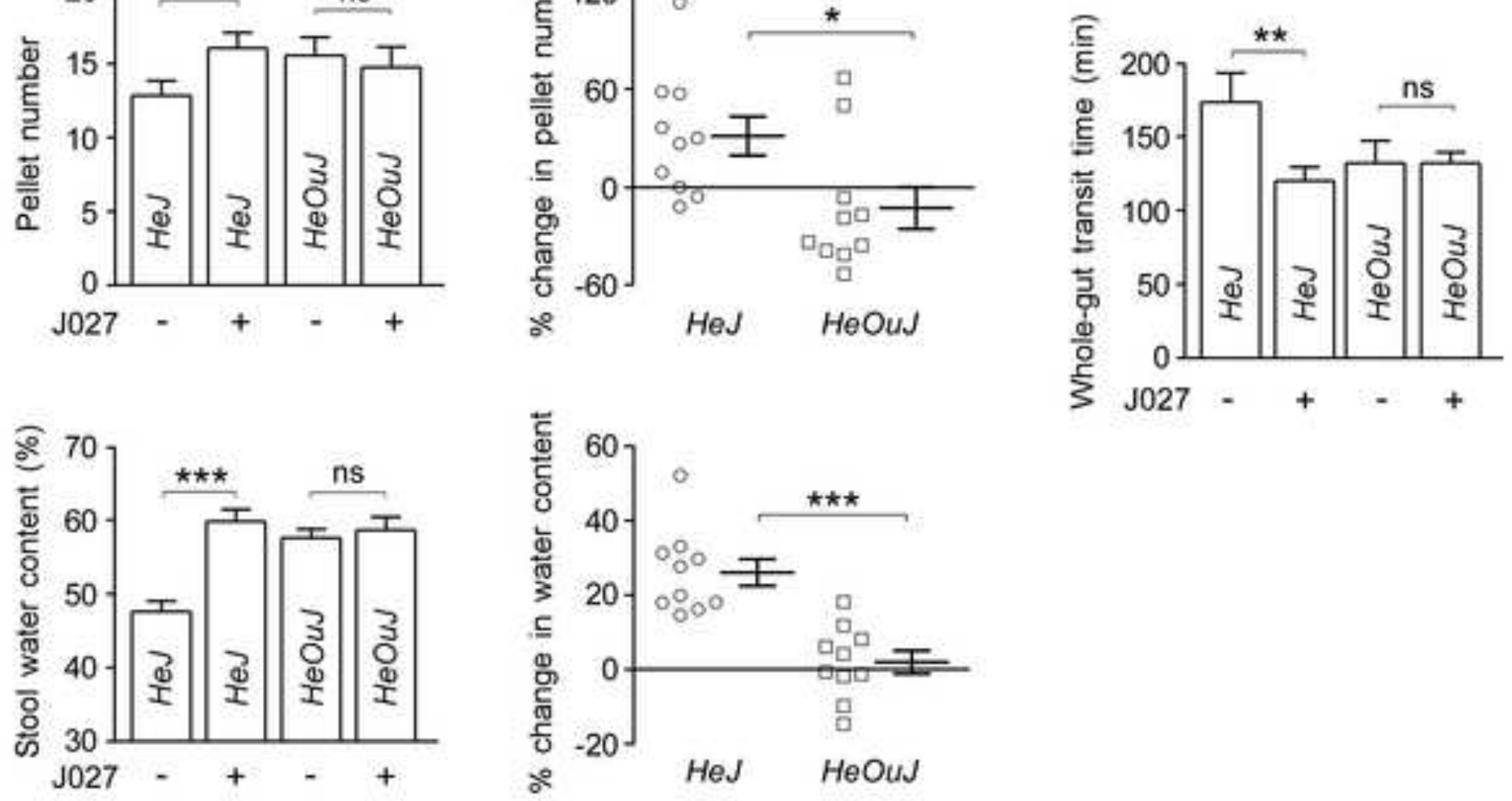

Figure 4 

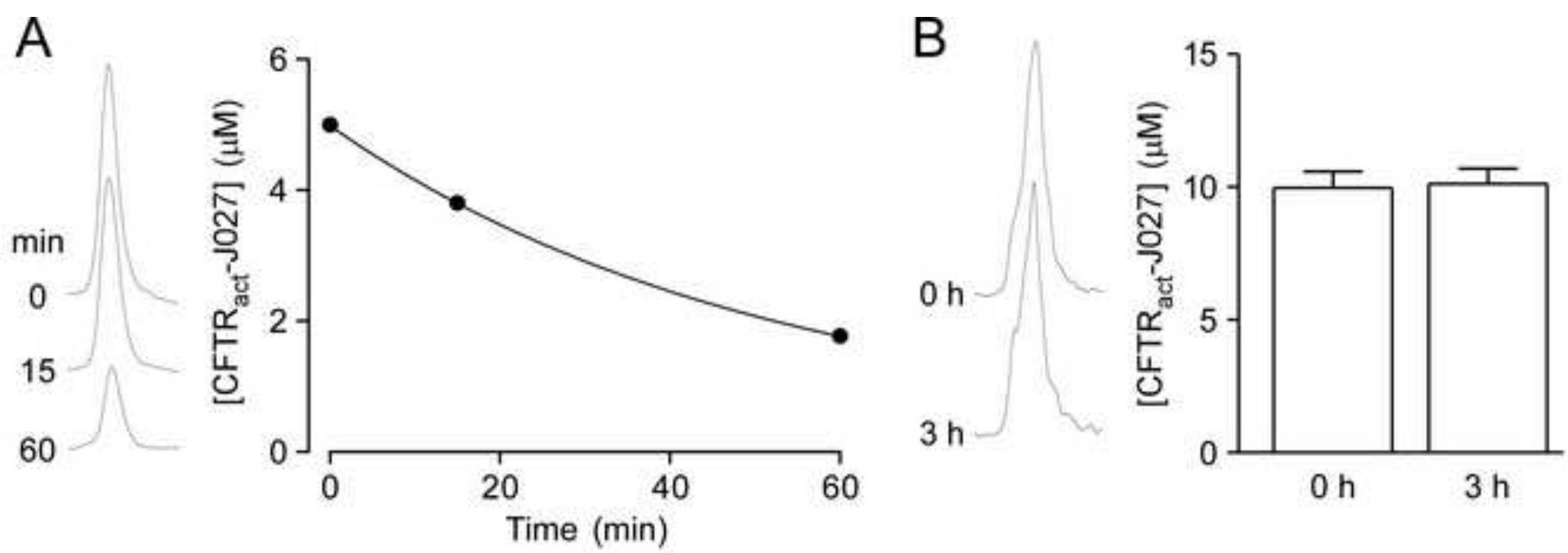

Figure 5 
A

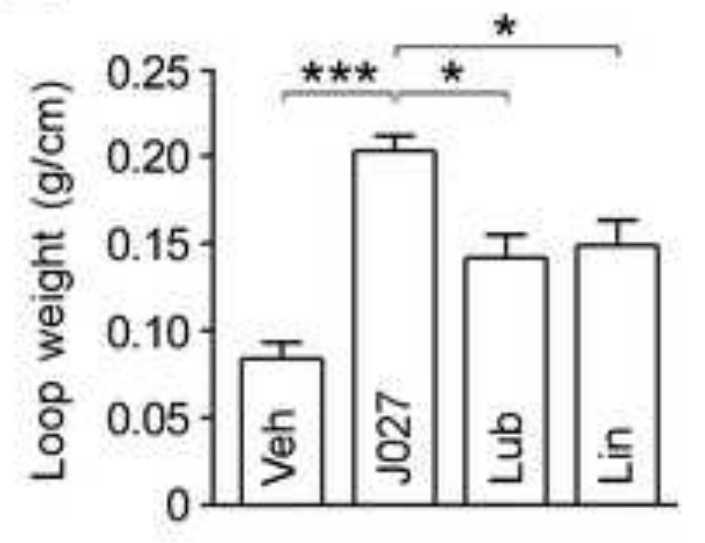

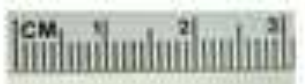
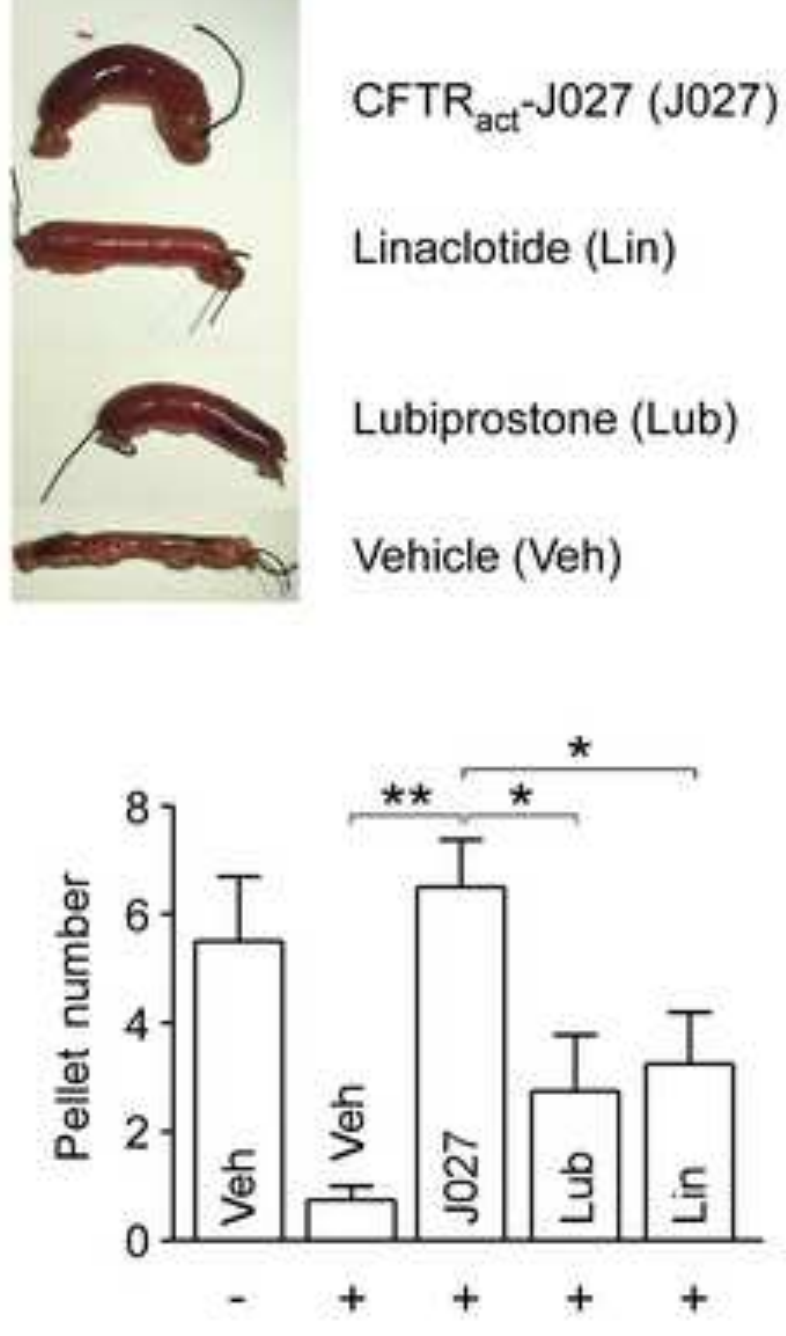

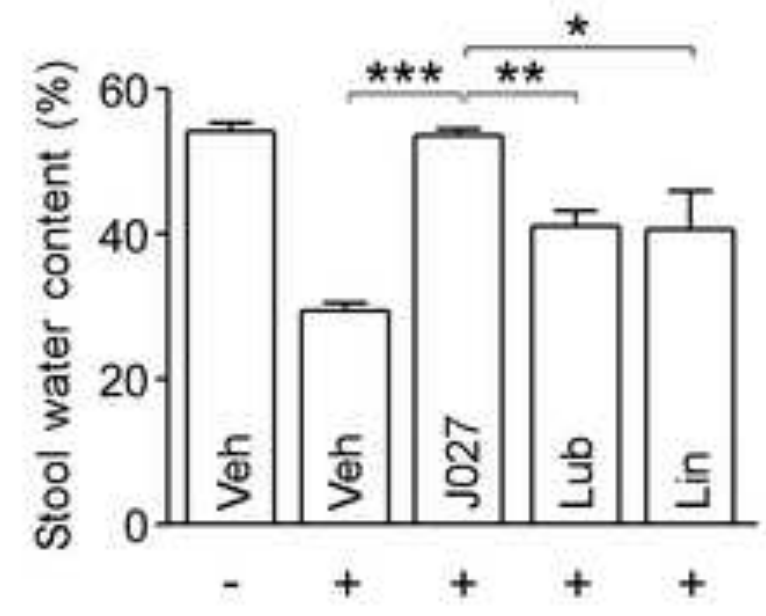

Figure 6

B

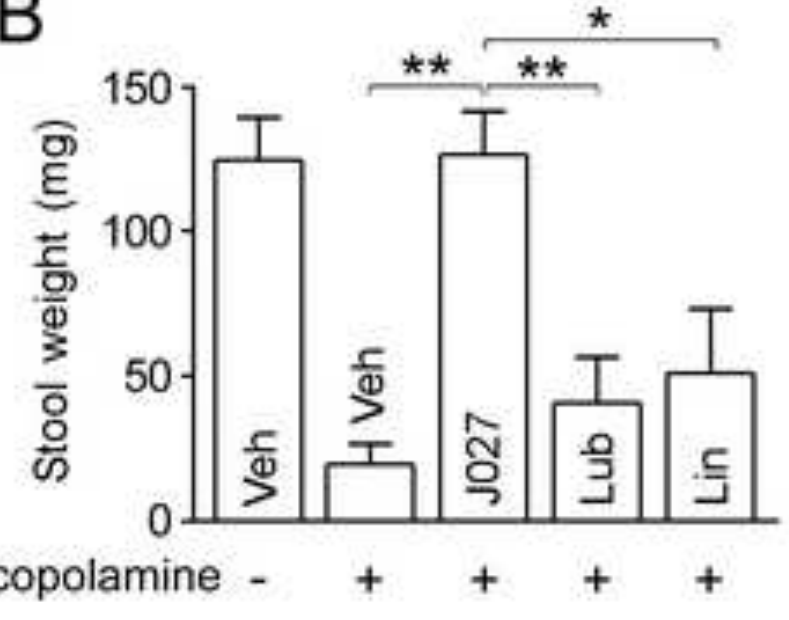


A

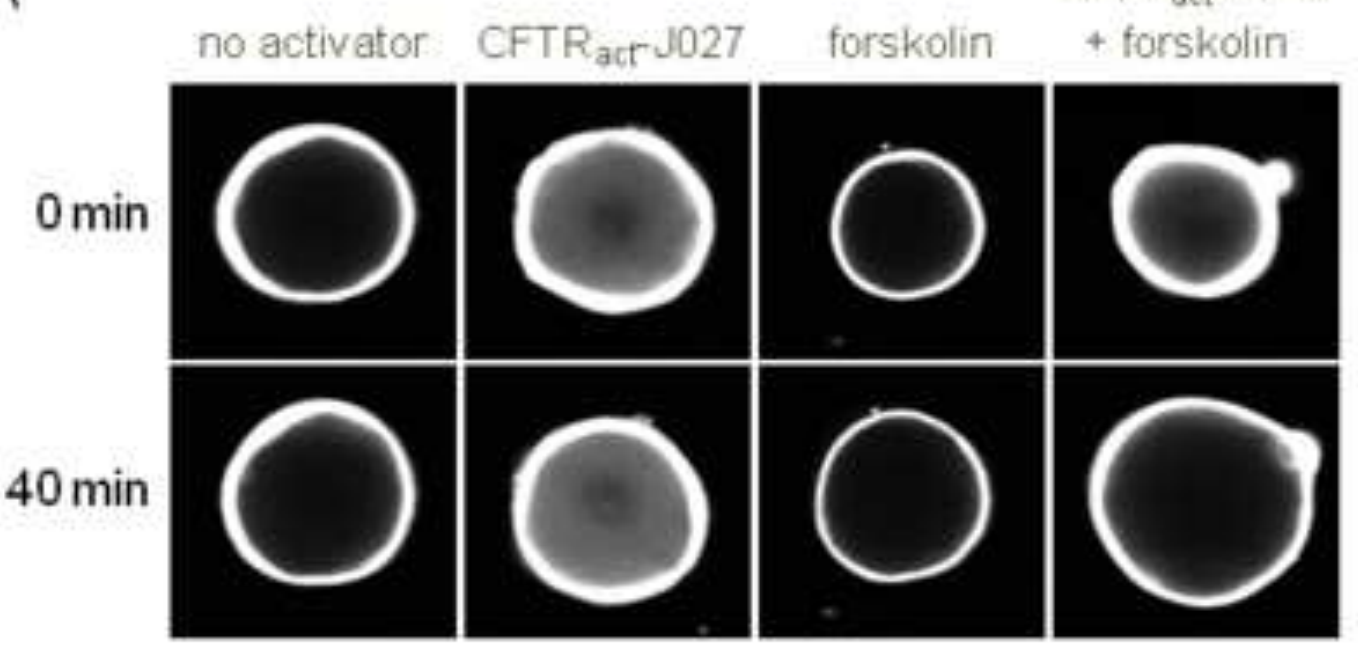

B

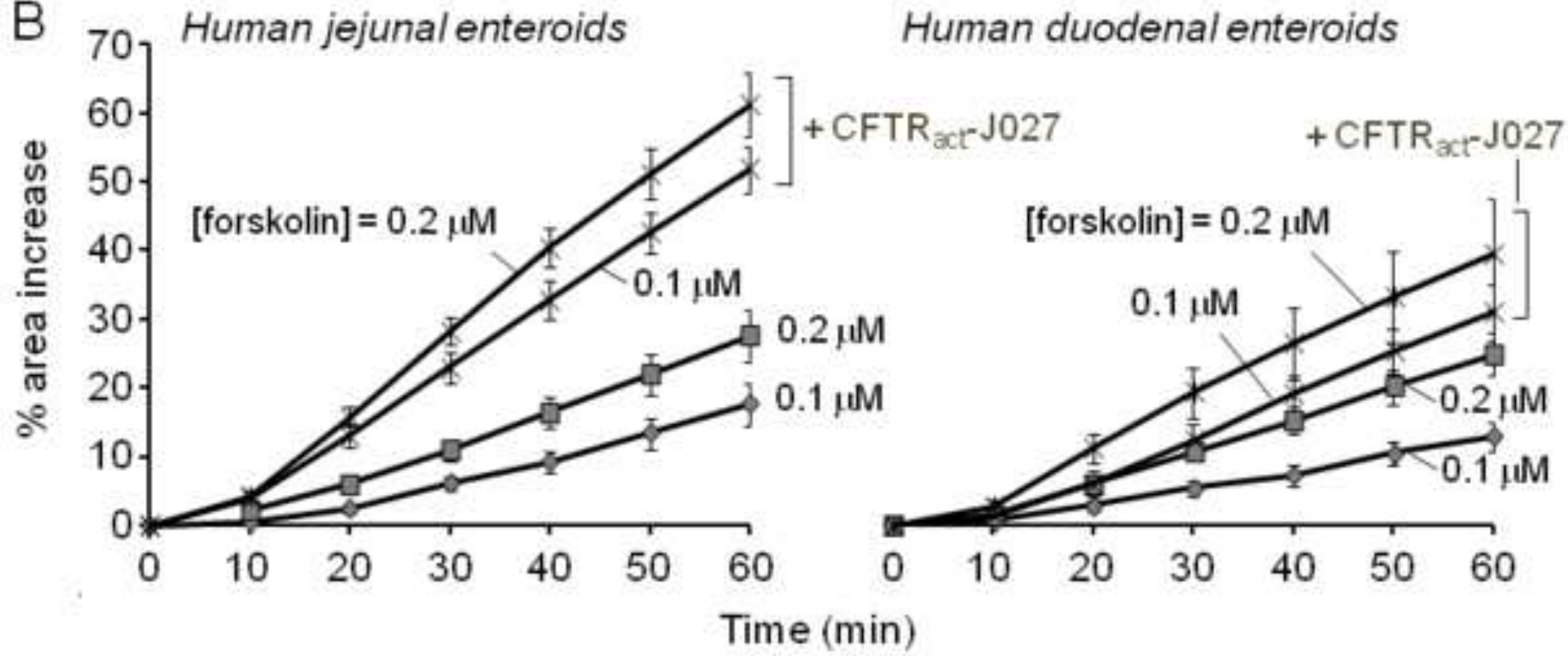

Human duodenal enteroids

Figure 7 